\title{
Molecular Characterization of Novel Family IV and VIII Esterases from a Compost Metagenomic Library
}

\author{
Jong-Eun Park, Geum-Seok Jeong, Hyun-Woo Lee and Hoon Kim * (D) \\ Department of Pharmacy, Research Institute of Life Pharmaceutical Sciences, Sunchon National University, \\ Suncheon 57922, Korea; 1200113@s.scnu.ac.kr (J.-E.P.); 1200058@s.scnu.ac.kr (G.-S.J.); \\ hwlee@rophibio.com (H.-W.L.) \\ * Correspondence: hoon@sunchon.ac.kr; Tel.: +82-617503751
}

Citation: Park, J.-E.; Jeong, G.-S.; Lee, H.-W.; Kim, H. Molecular Characterization of Novel Family IV and VIII Esterases from a Compost Metagenomic Library. Microorganisms 2021, 9, 1614. https://doi.org/10.3390/ microorganisms 9081614

Academic Editor: Dietmar Haltrich

Received: 8 July 2021

Accepted: 26 July 2021

Published: 29 July 2021

Publisher's Note: MDPI stays neutral with regard to jurisdictional claims in published maps and institutional affiliations.

Copyright: (c) 2021 by the authors. Licensee MDPI, Basel, Switzerland. This article is an open access article distributed under the terms and conditions of the Creative Commons Attribution (CC BY) license (https:/ / creativecommons.org/licenses/by/ $4.0 /)$.
Abstract: Two novel esterase genes, est $8 \mathrm{~L}$ and est13L, were isolated and identified from a compost metagenomic library. The encoded Est8L and Est13L had molecular masses of 33,181 and 44,913 Da consisting of 314 and 411 amino acids, respectively, without signal peptides. Est8L showed the highest identity (32.9\%) to a hyper-thermophilic carboxylesterase AFEST from Archaeoglobus fulgidus compared to other esterases reported and was classified to be a novel member of family IV esterases with conserved regions such as HGGG, DY, GXSXG, DPL, and GXIH. Est13L showed the highest identity (98.5\%) to the family VIII esterase Est7K from the metagenome library. Est8L and Est13L had the highest activities for $p$-nitrophenyl butyrate (C4) and p-nitrophenyl caproate (C6), respectively, and Est13L showed a broad substrate specificity for $p$-nitrophenyl substrates. Est8L and Est13L effectively hydrolyzed glyceryl tributyrate. The optimum temperatures for activities of Est8L and Est13L were identical $\left(40^{\circ} \mathrm{C}\right)$, and the optimum $\mathrm{pH}$ values were 9.0 and 10.0, respectively. Est13L showed higher thermostability than Est8L. Sephacryl S-200 HR chromatography showed that the native form of Est8L was a dimer. Interestingly, Est13L was found to be a tetramer, contrary to other family VIII esterases reported. Est8L was inhibited by 30\% isopropanol, methanol, and acetonitrile; however, Est13L was activated to $182.9 \%$ and $356.1 \%$, respectively, by $30 \%$ isopropanol and methanol. Est8L showed enantioselectivity for the $S$-form, but Est13L showed no enantioselectivity. These results show that intracellular Est8L and/or Est13L are oligomeric in terms of native forms and can be used for pharmaceutical and industrial applications with organic solvents under alkaline conditions.

Keywords: compost metagenomic library; family IV esterase; family VIII esterase; glyceryl tributyrate hydrolysis; oligomeric native form; organic solvent stability; broad substrate specificity

\section{Introduction}

Lipolytic enzymes, such as esterase (EC 3.1.1.1) and lipase (EC 3.1.1.3), hydrolyze the ester bond to carboxylic acid and alcohol. Esterases hydrolyze ester bonds in short chains with $<10$ carbons, whereas lipase hydrolyzes ester bonds in long chains with $>10$ carbons [1]. The application of esterases and lipases has been widely researched for chemical reactions and for application in the pulp and paper, cosmetics, and pharmaceutical industries [2,3]. Especially, esterases are applied for the improvement of the lipophilicity for ester prodrugs to increase cell wall penetration [4]. Bacterial esterases were first classified into eight families based on their primary amino acid sequences [1], and recently other families have been reported up to the 19th family [5].

The family IV esterase, which is called hormone-sensitive lipase (HSL), has a catalytic triad consisting of serine $(S)$, aspartic acid $(D)$, and histidine $(H)$. The serine residue in the catalytic triad is placed in the conserved GXSXG motif [6]. The bacterial HSL (bHSL) is a member of the $\alpha / \beta$ hydrolase family, which have similar structures, i.e., $\beta$-sheets covered by $\alpha$-helixes [7]. The bHSL is divided into two domains: cap and catalytic domains. The catalytic domain forms $\alpha$-helix and $\beta$-sheets with catalytic residues, and the cap domain 
is located on the upper side of the catalytic residues, which is associated with substrate recognition [8].

Three enzymes showing similarity to C- $\beta$-lactamase were first classified as family VIII members. The enzymes showed a typical conserved region SxxK. Their catalytic residues include $S$ and lysine $(\mathrm{K})$ in the SxxK motif and tyrosine $(\mathrm{Y})$, unlike other families containing $\mathrm{S}, \mathrm{D}$, and $\mathrm{H}[9]$.

Family IV and VIII esterases have been practically interested in the usage of ester synthesis, transesterification reactions, and hydrolysis of antibiotics [10,11].

Numerous bacterial esterases have been mainly isolated from metagenomic libraries. The metagenome is the collected genome of whole microorganisms in an environment without culture [12]. The DNA sample is directly extracted from sediments [13] and is called environmental DNA (eDNA) [14,15], serving extremely diverse genes. Numerous recent studies have focused on metagenomes from various environments, such as Antarctic soil [16], deep-sea [17], oil-polluted mudflat [18], volcano soil [19], and plant wasted water [8].

Compost contains diverse microorganisms producing various hydrolytic enzymes, including esterases and lipases [20]. Our library was constructed using compost metagenome, and 19 esterase-positive fosmid clones were obtained; then, the positive clones were mixed together, and extracted DNA was subcloned using cloning vector to obtain 18 positive subclones [21], two esterases of which, Est2K and Est7K, were characterized [21,22]. In this study, we identified two novel genes, est8L and est13L, from the library, and the encoded Est8L and Est13L esterases were characterized.

\section{Materials and Methods}

\subsection{Materials}

p-Nitrophenyl (pNP) esters from pNP-acetate (C2) to pNP-palmitate (C16), glyceryl esters (glyceryl tributyrate, glyceryl trioctanoate, and glyceryl trioleate), oils (fish oil and olive oil), acetylthiocholine iodide (ATCI), enantiomers [(R)- and (S)-methyl-3-hydroxy-2methyl-propionate], S-butyrylthiocholine iodide (BTCI), and 5,5'-dithiobis(2-nitrobenzoic acid) (DTNB) were purchased from Sigma-Aldrich (St. Louis, MO, USA). Columns for purification such as HiTrap Q HP $(5 \mathrm{~mL})$, t-butyl hydrophobic interaction chromatography (HIC) (1 mL), HiTrap capto MMC (1 mL), and HiPrep 16/60 Sephacryl S-200 HR were purchased from GE Healthcare (Uppsala, Sweden).

\subsection{Two Esterase-Positive Clones from the Compost Metagenome Library}

The compost metagenome was obtained from Yonghyun Nonghyub Compost Factory (Sachon, Korea), and completely fermented compost was used for metagenomic DNA extraction [21]. A metagenomic library was constructed using fosmid from the compost previously, and 19 esterase-positive fosmid clones were obtained [21]. By mixing, 18 positive subclones were obtained, and nine different lipolytic genes were identified by sequencing; two of them were selected based on the halo and the lowest similarities, and their characteristics were reported [21,22]. We selected two esterase-positive subclones further and their genes est8L and est13L. The transformants were incubated on LB agar plates containing $1 \%$ glyceryl tributyrate for $12 \mathrm{~h}$ at $25^{\circ} \mathrm{C}$.

\subsection{Sequence Analysis and Phylogenetic Tree}

Recombinant plasmids were isolated from the clones, and DNA sequences were determined by the dideoxy method (http:/ / www.solgent.com/english/sub03030101, accessed on 25 July 2021) at Solgent (Daejeon, Korea). Amino acid sequences and conserved regions were analyzed by BLASTp of NCBI (http:/ / www.ncbi.nlm.nih.gov, accessed on 12 April 2021). Putative signal peptides were predicted by SignalP 5.0 in CBS (http:/ / www.cbs.dtu.dk/services/SignalP/, accessed on 12 April 2021), and molecular mass and theoretical pI were calculated using the ExPASy ProtParam tool (http: // web.expasy.org/protparam, accessed on 11 April 2021). Multiple sequence alignments 
were analyzed and performed using the Clustal W method in DNA/MAN (Lynnon Biosoft, version 4.11, Quebec, Canada). Phylogenetic trees were constructed by MEGA version $X[23]$ using the maximum likelihood method.

\subsection{Preparation of Crude Enzymes}

Esterase-positive clones were inoculated in $200 \mathrm{~mL} \mathrm{LB}$ broth and incubated for $15 \mathrm{~h}$ at $200 \mathrm{rpm}$ and $37^{\circ} \mathrm{C}$. After incubation, the medium was centrifuged for $15 \mathrm{~min}$ at $6000 \times g$ and $4{ }^{\circ} \mathrm{C}$. The pellet was washed two times with $20 \mathrm{~mL}$ of $20 \mathrm{mM}$ Tris- $\mathrm{HCl}(\mathrm{pH} \mathrm{8.0)}$ and centrifuged for $5 \mathrm{~min}$ at $6000 \times g$ and $4{ }^{\circ} \mathrm{C}$. The pellet was resuspended in $5 \mathrm{~mL}$ of the same buffer and sonicated three times under an amplitude of $38 \%$ and pulse on for 1 sec and pulse off for $1 \mathrm{sec}$ for $1 \mathrm{~min}$ using a microtip equipped on a sonicator (VCX500, Sonics \& Materials, Newtown, CT, USA). After centrifugation for $15 \mathrm{~min}$ at $6000 \times g$ and $4{ }^{\circ} \mathrm{C}$, the supernatant was collected as a crude enzyme.

\subsection{Purification of the Enzymes and Activity Staining}

The crude enzymes were separated further using a Biologic LP System (Bio-Rad). HiTrap Q anion exchange chromatography was performed using $20 \mathrm{mM}$ Tris- $\mathrm{HCl}$ ( $\mathrm{pH}$ 8.0) as a low buffer and $20 \mathrm{mM}$ Tris- $\mathrm{HCl}(\mathrm{pH}$ 8.0) containing $1 \mathrm{M} \mathrm{NaCl}$ as a high buffer at a flow rate of $1.0 \mathrm{~mL} / \mathrm{min}$ for $90 \mathrm{~min}$. The HiTrap t-butyl HIC was employed as a second column using $50 \mathrm{mM}$ sodium phosphate ( $\mathrm{pH} 7.0)$ buffer containing $1.5 \mathrm{M}\left(\mathrm{NH}_{4}\right)_{2} \mathrm{SO}_{4}$ as a high buffer and $50 \mathrm{mM}$ sodium phosphate ( $\mathrm{pH}$ 7.0) buffer as a low buffer at a flow rate of $1.0 \mathrm{~mL} / \mathrm{min}$ for $60 \mathrm{~min}$. The HiTrap capto MMC was performed for further purification using $25 \mathrm{mM}$ sodium acetate ( $\mathrm{pH} 4.5$ ) buffer as a low buffer and $50 \mathrm{mM}$ sodium phosphate (pH 7.0) buffer including $1 \mathrm{M} \mathrm{NaCl}$ as a high buffer at a flow rate of $0.5 \mathrm{~mL} / \mathrm{min}$ for $2 \mathrm{~h}$. Size exclusion chromatography was performed using Sephacryl S-200 with $50 \mathrm{mM}$ sodium phosphate ( $\mathrm{pH} 7.0$ ) containing $0.15 \mathrm{M} \mathrm{NaCl}$ at a flow rate of $0.5 \mathrm{~mL} / \mathrm{min}$ for $240 \mathrm{~min}$. Molecular mass standards were used with $\beta$-amylase, bovine serum albumin (BSA), and trypsinogen $(200,66.4$, and $24.0 \mathrm{kDa}$, respectively).

To confirm the activity and molecular mass of each cloned enzyme at the same time, HiTrap Q pools were separated by native polyacrylamide gel electrophoresis (PAGE) without sodium dodecyl sulfate (SDS) and heat treatment of the sample, and the gel was analyzed by activity staining. The native gel was soaked with $50 \mathrm{mM}$ Tris- $\mathrm{HCl}$ ( $\mathrm{pH}$ 8.0) for $30 \mathrm{~min}$, tightly overlapped to a $3 \%$ agar strip containing $1.5 \%$ glyceryl tributyrate, wrapped, and incubated for $30 \mathrm{~min}$ at $40{ }^{\circ} \mathrm{C}$ until a clear band was visible. The region of the gel corresponding to the clear band of the strip was sliced, chopped, and eluted in $20 \mathrm{mM}$ Tris- $\mathrm{HCl}$ buffer overnight at $4{ }^{\circ} \mathrm{C}$. After centrifugation for $5 \mathrm{~min}$ at $10,000 \times g$ and $4{ }^{\circ} \mathrm{C}$, the supernatant was collected and used as a purified enzyme. To verify the purity, SDS-PAGE was performed by loading the samples in 11.5\% acrylamide gel [24]; then, proteins in the gel were stained with silver. Protein concentration was determined by the Bradford assay [25].

\subsection{Enzyme Assays}

The esterase activity was calculated as the amount of $p$-nitrophenol, which is the product of the reaction between esterase and $p$-nitrophenyl ester. The enzyme was added into $50 \mathrm{mM}$ Tris- $\mathrm{HCl}$ buffer ( $\mathrm{pH} 8.0$ ) containing $1 \mathrm{mM} \mathrm{pNPB}$. The absorbances of the reaction mixtures were measured continuously for $2 \mathrm{~min}$ at $400 \mathrm{~nm}$ and $25^{\circ} \mathrm{C}$ as a standard assay using the kinetic mode of a spectrophotometer (Optizen, K-Lab, Daejon, Korea). One unit of the enzyme activity was the enzyme amount producing $1 \mu \mathrm{mol}$ of $p$-nitrophenol per minute using a molar extinction coefficient of $16,400 / \mathrm{M} / \mathrm{cm}$ at $\mathrm{pH} 8.0$. Acetylcholinesterase and butyrylcholinesterase activities were measured using ATCI and BTCI, respectively, as described previously [26]. Enzymes reacted with $0.5 \mathrm{mM}$ substrate and $0.5 \mathrm{mM}$ DTNB in $100 \mathrm{mM}$ sodium phosphate ( $\mathrm{pH} 7.5$ ), and the reaction was monitored continuously for $10 \mathrm{~min}$ at $412 \mathrm{~nm}$ and $25^{\circ} \mathrm{C}$ in the kinetic mode. 


\subsection{Characterization of Enzymes}

The optimum temperature was identified using the standard assay method at 20,30, $40,50,60$, and $70{ }^{\circ} \mathrm{C}$. The optimum $\mathrm{pH}$ was determined using $50 \mathrm{mM}$ universal buffer (boric acid/citric acid/trisodium orthophosphate) in the range of $\mathrm{pH} 6.0$ and 11.0, and molecular extinction of each $\mathrm{pH}$ was used, as described previously [18]. The heat stability of the purified enzyme was analyzed by preincubating at $30,40,50$, and $60^{\circ} \mathrm{C}$ for $1 \mathrm{~h}$ at designated times.

Substrate specificity was investigated using $1 \mathrm{mM} p$-NP esters (C2 C16). Five different concentrations of substrate, i.e., pNPB (C4), were used for the kinetic study, and Lineweaver-Burk plots were constructed to calculate the $K_{m}$ and $V_{\max }$.

The ion effect on enzyme activity was investigated by adding $\mathrm{Na}^{+}, \mathrm{K}^{+}, \mathrm{Mg}^{2+}, \mathrm{Ca}^{2+}$, $\mathrm{Ba}^{2+}, \mathrm{Mn}^{2+}, \mathrm{Fe}^{2+}, \mathrm{Co}^{2+}, \mathrm{Cu}^{2+}$, and $\mathrm{Zn}^{2+}$ ions at 2 and $5 \mathrm{mM}$ of concentrations. The organic solvent stability of the enzyme was observed at $5 \%$ or $30 \%$, such as methanol, isopropanol, and acetonitrile. The detergent stability was analyzed at 1\% SDS or Triton-X-100.

The lipid hydrolysis activity of the enzyme was confirmed using a $\mathrm{pH}$ shift assay [27] using $1 \%$ oils (fish oil and olive oil) or glyceryl triesters (glyceryl tributyrate, glyceryl trioctanoate, and glyceryl trioleate) and $0.1 \%$ phenol red in $20 \mathrm{mM}$ Tris- $\mathrm{HCl}(\mathrm{pH} 8.0)$. Absorbance was measured using a spectrophotometer in the kinetic mode at every $5 \mathrm{~min}$ for $60 \mathrm{~min}$ at $560 \mathrm{~nm}$ and $25^{\circ} \mathrm{C}$, and the amount of remaining substrate was determined. To confirm the enantioselectivity of the enzyme, $1 \%(R)$ - or (S)-methyl-3-hydroxy-2-methylpropionate was used as a substrate [18].

\subsection{Accession Numbers of the Est8L and Est13L}

The sequences of est8L and est13Lwere deposited under accession numbers MZ484407 and MZ484408 at GenBank, respectively.

\section{Results}

\subsection{Sequence Analyses and Multiple Alignments of Est8L and Est13L}

The positive clones YH-E8 and YH-E13 were selected in this study based on their halo sizes. The insert DNA of YH-E8 was 3202 bp in length, and an open reading frame (ORF) of $945 \mathrm{bp}$ coding an esterase was identified and named est8L. The insert DNA of YH-E13 was $3871 \mathrm{bp}$ long, and an ORF of an esterase consisting of $1236 \mathrm{bp}$ was identified and named est13L. The encoded proteins Est8L and Est13L had molecular weights of 33,181 and 44,913 Da, respectively, were consisted of 314 and 411 amino acid residues, respectively; their theoretical pI values were 4.66 and 6.34, respectively. Est8L and Est13L had no signal peptides, as observed by SignalP-5.0 analysis. Analysis of the phylogenetic tree predicted that Est8L was a novel member of family IV esterases, and Est13L was a novel member of family VIII esterases (Figure 1). A BLASTp search showed that Est8L has the highest identity $(100 \%)$ for an alpha/beta hydrolase from Sphingorhabdus sp. (GenBank MBF6602187) in annotated sequences. However, Est8L showed the highest identity (32.9\%) to a hyper-thermophilic carboxylesterase AFEST from Archaeoglobus fulgidus compared to other esterases enzymatically reported to date. Est13L had the highest identity $(98.5 \%)$ for the family VIII esterase Est7K from an uncultured bacterium (AJN91095).

In multiple sequence alignment (MSA) of Est8L with other family IV lipolytic enzymes, some conserved regions such as HGGG (corresponding to 87-89 amino acid residues), DY (118-119), GXSAG (160-164), DPL (254-256), and GXIㅍ (281-284) were confirmed, and the underlined serine $(\mathrm{S})$, aspartic acid $(\mathrm{D})$, and histidine $(\mathrm{H})$ were predicted to form a catalytic triad of alpha/beta hydrolase (Figure 2a). From the MSA of Est13L with other family VIII lipolytic enzymes, numerous conserved regions such as SMTK (73-76), IPE (102-104), LXXXPGXXWX్S (181-192), DXXGXXXEXXSG (196-207), and PLGM (221-224) were identified. Similar to most of the family VIII esterases, Est13L had XXSXG (354-358) instead of GXSXG, which is commonly observed in esterase. However, in family VIII esterases, the serine residue of the catalytic triad is derived from the SMTK motif, not XXSXG (Figure 2). 


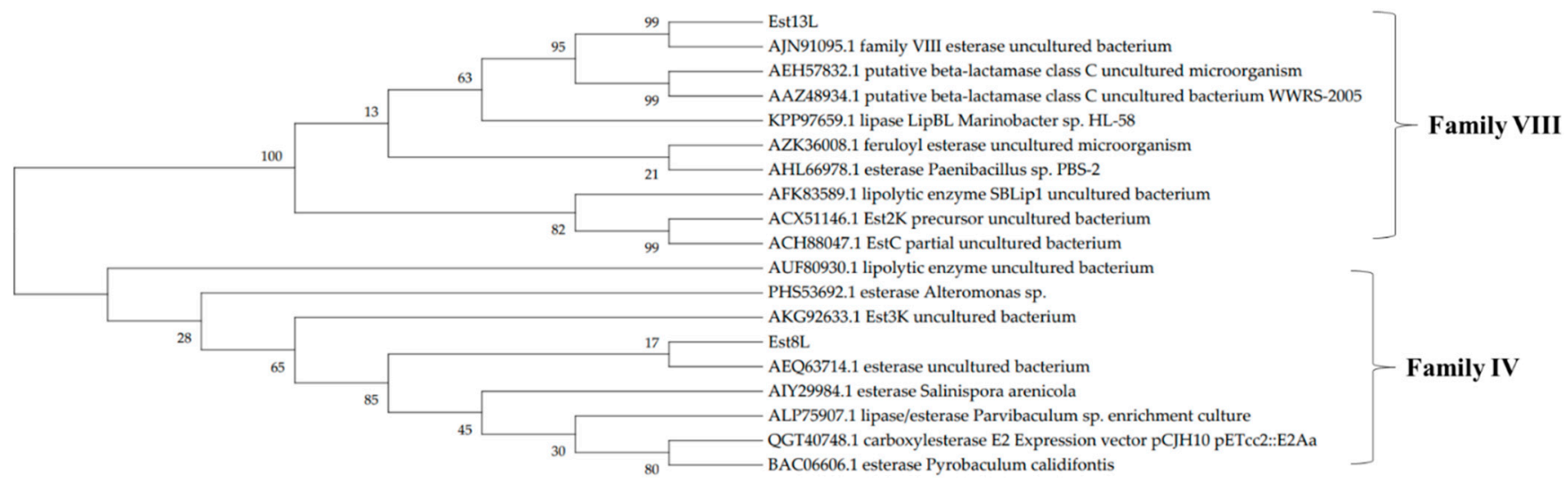

Figure 1. A phylogenetic tree of Est8L and Est13L using the maximum likelihood method. The number at the node shows bootstrap percentages of 1000 replicates. The accession numbers were from GenBank.

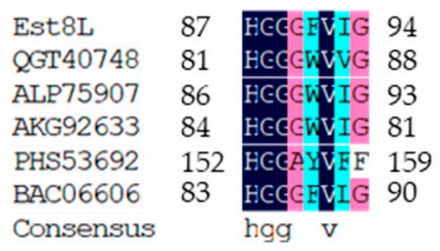

Consensus
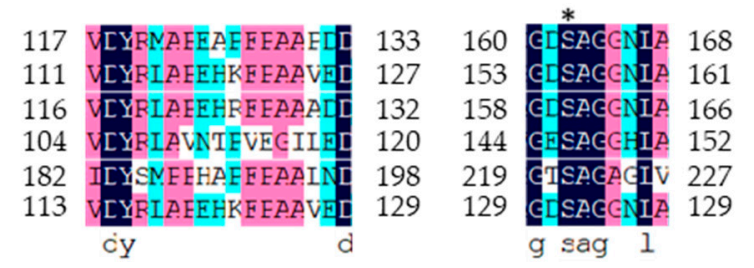
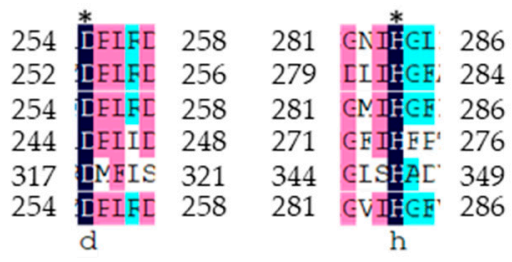

(a)

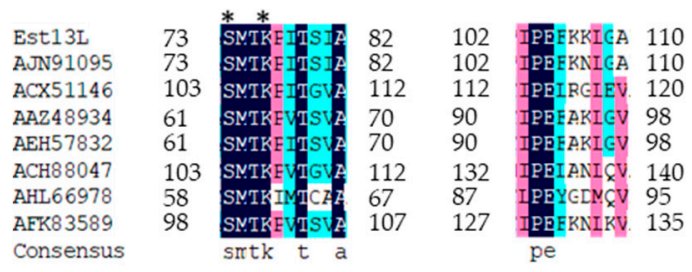

AFK83589

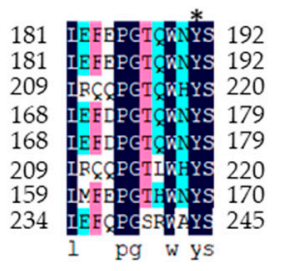

(b)
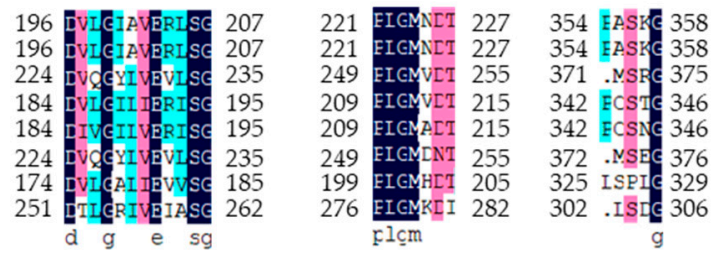

Figure 2. Multiple sequence alignments of Est8L (a) and Est13L (b) using the Clustal W method in DNA/MAN. The asterisks represent the catalytic triads. Family IV esterases: QGT40748, carboxyl esterase E2 (expression vector pCJH10_pETcc2::E2Aa); ALP75907, lipase/esterase (Parvibaculum sp. enrichment culture); AKG92633, Est3K (uncultured bacterium); PHS53692, esterase (Altermonas sp.); esterase (Pyrobaculum calidifontis). Family VIII esterases: AJN91095, family VIII esterase (Est7K) (uncultured bacterium); ACX51146, Est2K precursor (uncultured bacterium); AAZ48934, putative beta-lactamase class C (uncultured bacterium WWRS-2005); AEH57832, putative beta-lactamase class C (uncultured microorganism); ACH88047, EstC, partial (uncultured bacterium); AHL66978, esterase (Paenibacillus sp. PBS-2); lipolytic enzyme SBLip1 (uncultured bacterium).

\subsection{Purification of Est8L and Est13L}

Each enzyme of Est8L and Est13L was purified using HiTrap Q as the first column. Both enzymes were bound to the resin and eluted through a gradient step (Supplementary Figures S1a and S2a). Next, a t-butyl HIC column was employed as a second column; however, recovery of Est8L activity was too low to be detectable, whereas Est13L was successfully purified. Therefore, HiTrap capto MMC and HIC columns were used as the second columns for Est8L and Est13L, respectively (Supplementary Figures S1b and S2b). In SDS-PAGE, purified Est8L was observed with smear bands at the predicted position of the gel, i.e., corresponding to $\sim 33 \mathrm{kDa}$ (Figure 3a), probably because of the internal proteolytic cleavage of foreign proteins as in other cases [28-32]. 
Est13L appeared as a major band at the predicted position, corresponding to $\sim 45 \mathrm{kDa}$ (Figure 3b).

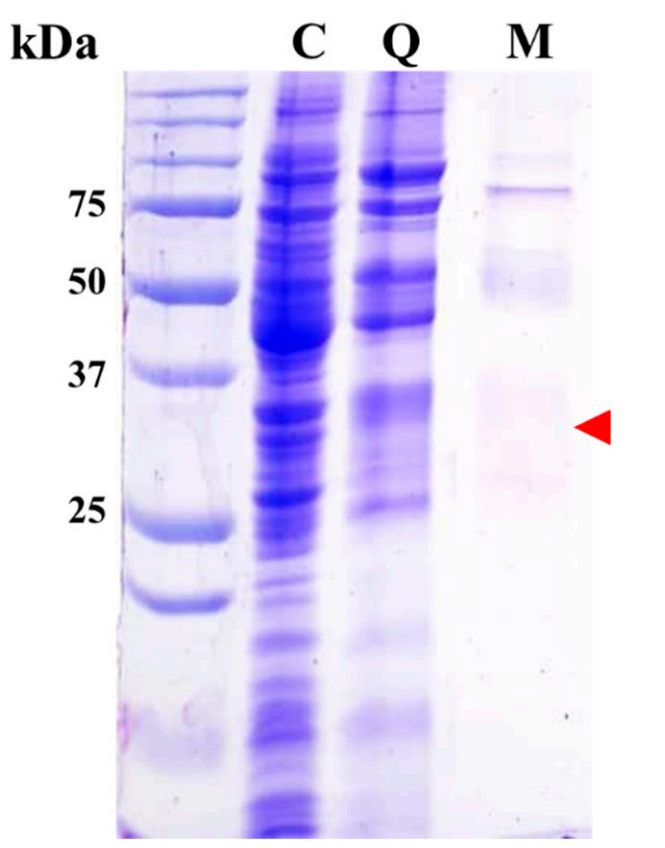

(a)

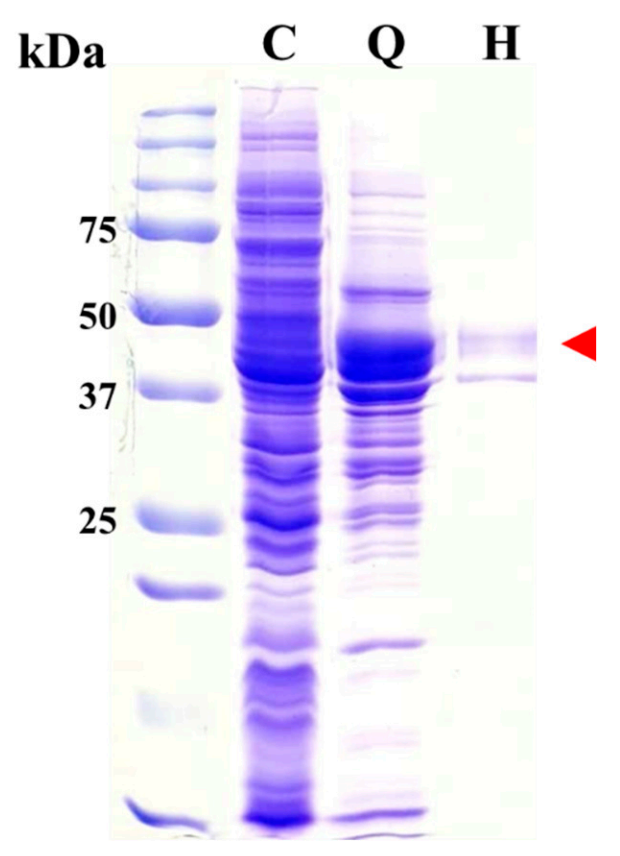

(b)

Figure 3. Gels of purified Est8L (a) and Est13L (b) after SDS-PAGE and staining with Coomassie blue. Red arrows in (a) and (b) indicate the predicted positions of Est8L and Est13L, respectively. C, crude extract; Q, HiTrap Q fraction; M, HiTrap capto MMC fraction; H, t-butyl HIC fraction.

Through this procedure, the purification fold and yield of Est8L were $11.9 \%$ and $12.1 \%$, respectively, and those of Est13L were $40.3 \%$ and $43.2 \%$, respectively (Table 1).

Table 1. Purification of Est8L and Est13L using chromatographic procedures.

\begin{tabular}{ccccc}
\hline Enzyme. & Preparation & Specific Activity (U/mg) & Purification (Fold) & Yield (\%) \\
\hline \multirow{3}{*}{ Est8L } & Crude extract & 32.6 & 1.0 & 100 \\
& HiTrap Q & 268.6 & 8.2 & 61.8 \\
& MMC & 388.6 & 11.9 & 12.1 \\
\hline \multirow{3}{*}{ Est13L } & Crude extract & 1.05 & 1.00 & 100 \\
& HiTrap Q & 10.79 & 10.3 & 68.6 \\
& HIC & 42.33 & 40.3 & 43.2 \\
\hline
\end{tabular}

To confirm the size of each cloned enzyme, activity staining was performed using HiTrap Q pools after native-PAGE. In the overlapped-agar strips, the respective active bands of Est8L and Est13L were observed (Figure 4a,b). The region of the gel corresponding to the clear band of the strip was sliced, and then proteins were recovered and analyzed by SDS-PAGE to determine their molecular masses through silver staining. As a result, Est8L and Est13L were observed at the bands corresponding to 33 and $45 \mathrm{kDa}$, respectively, similar to their expected values (Figure $4 c, d$ ). 


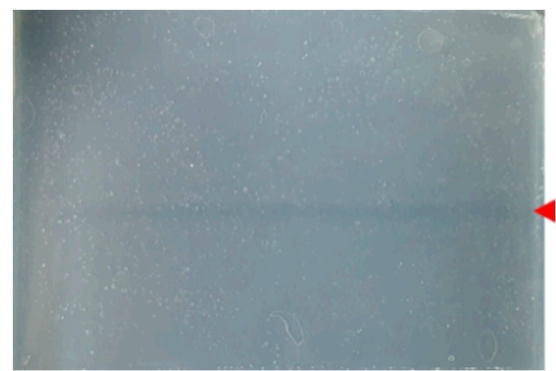

(a)

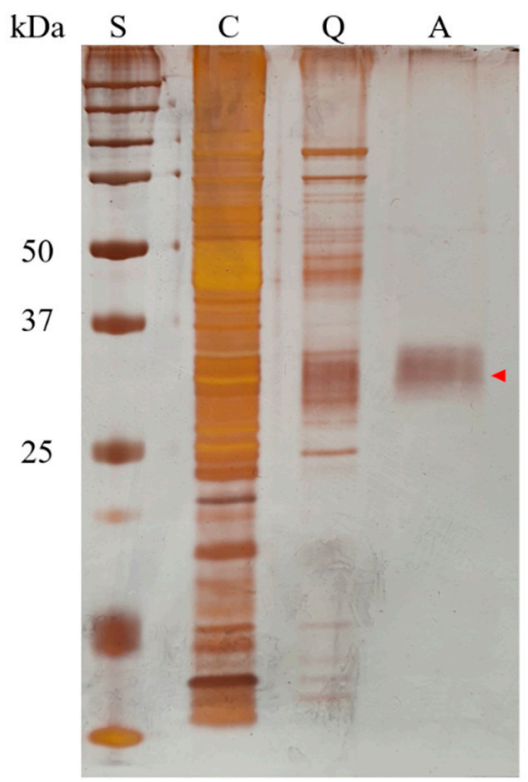

(c)

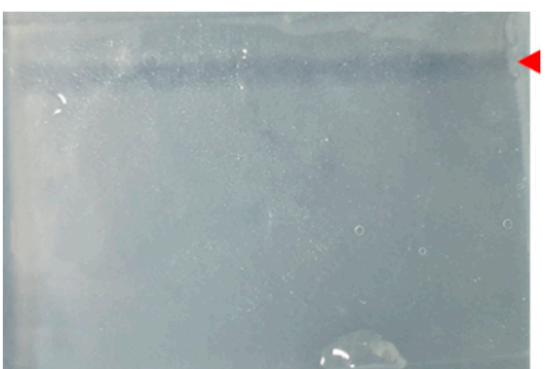

(b)

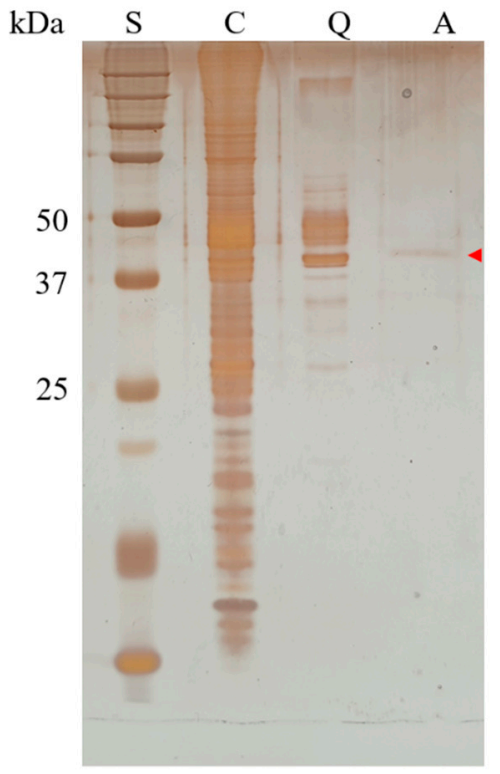

(d)

Figure 4. Activity staining of Est8L (a) and Est13L (b) onto the agar strips after native-PAGE and analysis of recovered Est8L (c) and Est13L (d) eluted from the activity-stained agar strips using SDSPAGE and staining with silver nitrate. Native-PAGE was performed using the HiTrap $Q$ fraction with the highest activity, and activity staining was performed according to the procedure described in the Materials and Methods. Red arrows in $(\mathbf{a}, \mathbf{b})$ represent the active bands for the enzymes. Red arrows in $(\mathbf{c}, \mathbf{d})$ indicate the predicted positions of Est8L and Est13L, respectively. S, size markers; C, crude extracts; Q, fraction pools from HiTrap Q column chromatography; A, pools from activity staining.

\subsection{Determination of Molecular Masses of Native Est8L and Est13L}

To determine the molecular masses of native forms of Est8L and Est13L, size exclusion chromatography using a Sephacryl S-200 HR column was performed. The elution volumes of Est8L and Est13L were 61.5 and $47.5 \mathrm{~mL}$, respectively, and their molecular masses were predicted to be 67.2 and $160.0 \mathrm{kDa}$, respectively. These results indicated that their native forms are a dimer and tetramer, respectively (Table 2).

Table 2. Molecular masses of native Est8L and Est13L determined by Sephacryl S-200 HR.

\begin{tabular}{cccc}
\hline & Fraction Volume $(\mathbf{m L})$ & Molecular Mass (kDa) & $\log$ Mw \\
\hline B-amylase & 46 & 200.0 & 2.30 \\
BSA & 58 & 66.4 & 1.82 \\
Trypsinogen & 78 & 24.0 & 1.38 \\
\hline Est8L & 61.5 & $67.2 \pm 2.9$ & 1.83 \\
\hline Est13L & 47.5 & $160.0 \pm 7.3$ & 2.20 \\
\hline
\end{tabular}

The means \pm SEs were calculated via duplicate experiments. 


\subsection{Properties of Est8L and Est13L}

Est8L and Est13L were optimally active at $40{ }^{\circ} \mathrm{C}$, and the optimum $\mathrm{pH}$ values of Est8L and Est13L were 9.0 and 10.0, respectively, indicating that both are alkaline esterases (Figure 5). Est13L had better thermal stability with a half-life of $3.2 \mathrm{~min}$ at $60^{\circ} \mathrm{C}$, whereas Est8L showed a half-life of $3.2 \mathrm{~min}$ at $50^{\circ} \mathrm{C}$ (Figure 6).

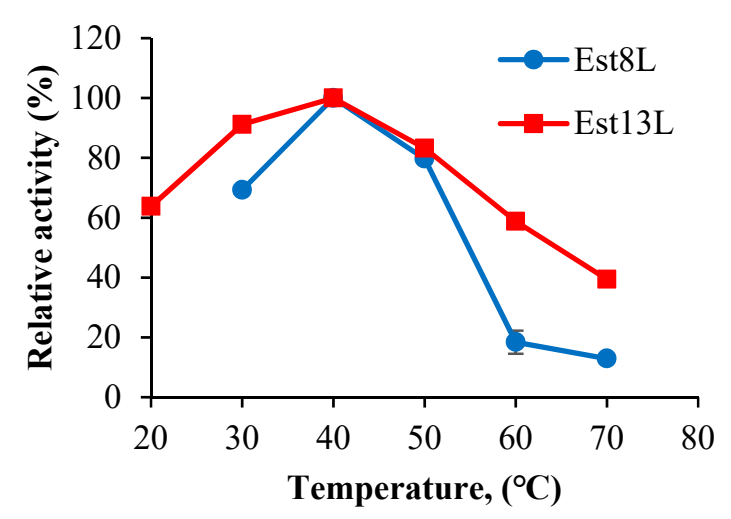

(a)

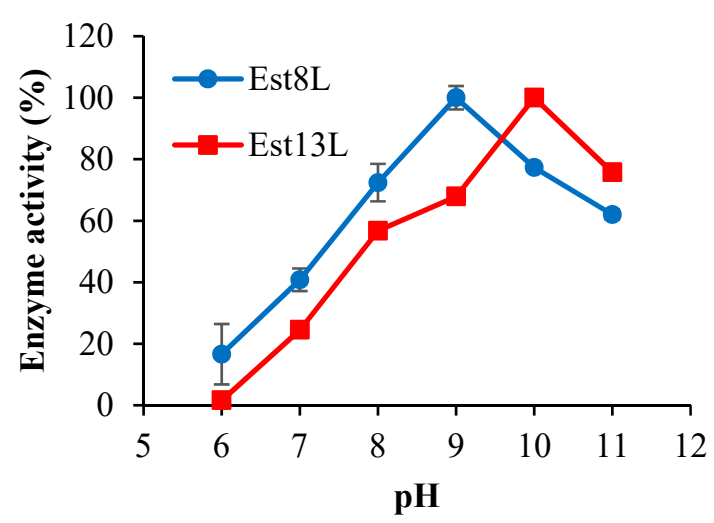

(b)

Figure 5. Optimum temperatures (a) and optimum $\mathrm{pH}$ values (b) of Est8L and Est13L.

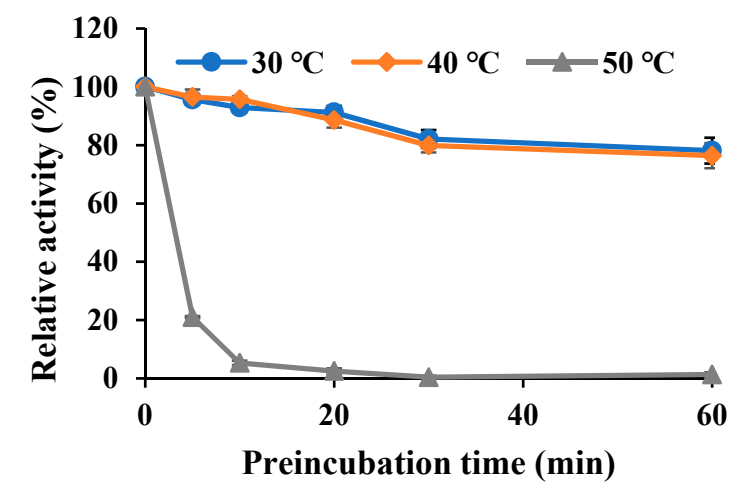

(a)

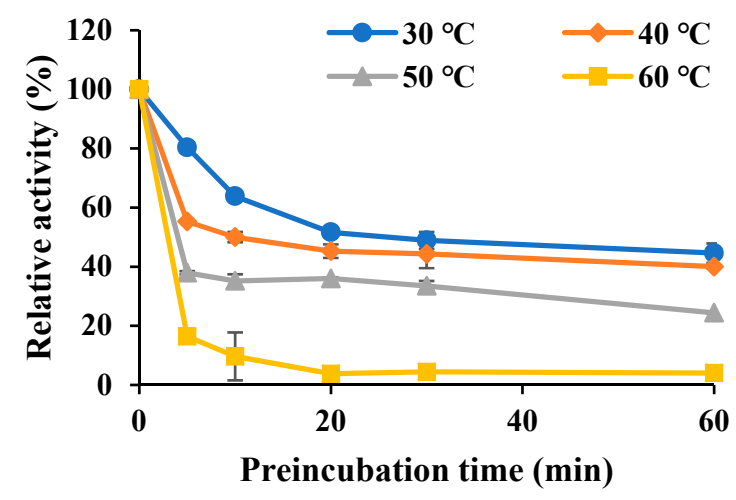

(b)

Figure 6. Thermal stabilities of Est8L (a) and Est13L (b). The enzyme was preincubated at the designated temperatures for the indicated times prior to activity measurements.

Est8L mostly preferred pNPB (C4), followed by pNP-caproate (C6), pNP-octanoate (C8), and pNP-acetate (C2) with relative activities of 76.5\%, $41.8 \%$, and $30.4 \%$, respectively, and showed no significant activities toward other longer substrates (Figure 7). Est13L showed the highest activity for $C 6$, similar to $C 8$ and $C 4$ with relative activities of $99.0 \%$ and $98.4 \%$, respectively, and exhibited a moderate activity toward pNP-caprate (C10), C2, pNP-laurate (C12), pNP-myristate (C14), and pNP-palmitate (C16) with relative activities of $57.6 \%, 46.8 \%, 39.6 \%, 39.3 \%$, and $20.0 \%$, respectively, indicating that Est $13 \mathrm{~L}$ had a broad substrate specificity (Figure 7). In contrast, Est8L and Est13L had no significant activity for ATCI and BTCI, which were cholinesterase substrates (Figure 7). 


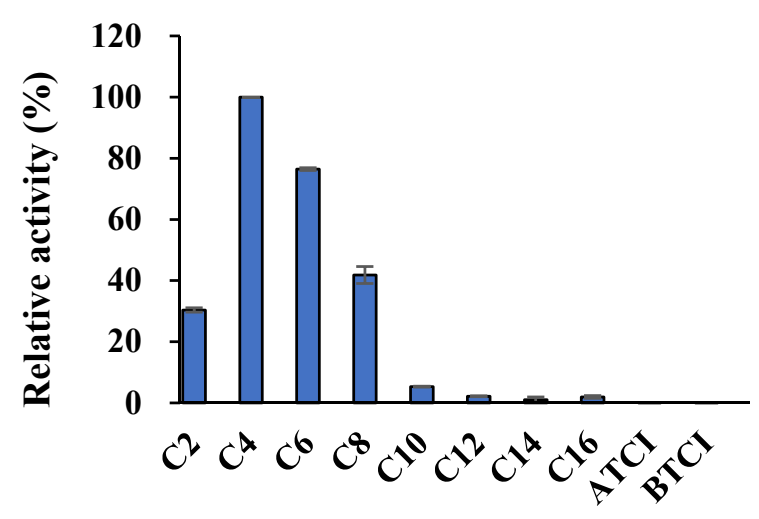

(a)

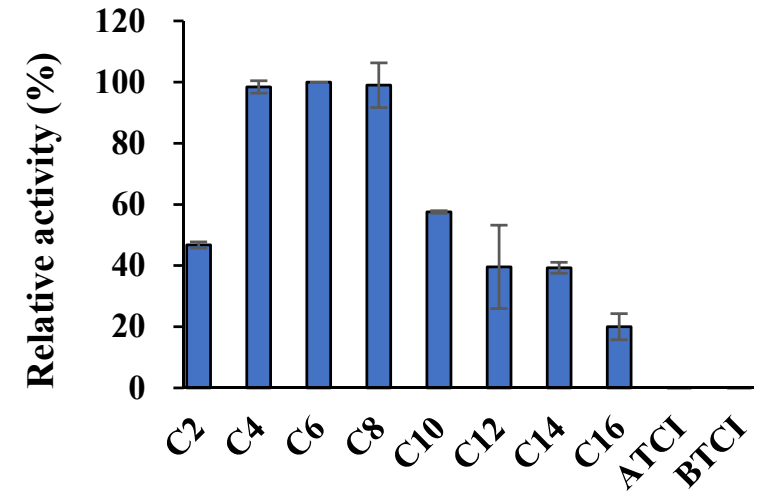

(b)

Figure 7. Substrate specificities of Est8L (a) and Est13L (b). The relative activities were calculated as percentages of the highest activity.

In a kinetic study for $\mathrm{pNPB}(\mathrm{C} 4)$ as a substrate, the $\mathrm{K}_{\mathrm{m}}$ values of Est8L and Est13L were $0.15 \pm 0.020$ and $0.029 \pm 0.0018 \mathrm{mM}$, respectively, and the $\mathrm{V}_{\max }$ values were $496.8 \pm 64.72$ and $22.9 \pm 1.51 \mathrm{U} / \mathrm{mg}$, respectively (Figure 8).

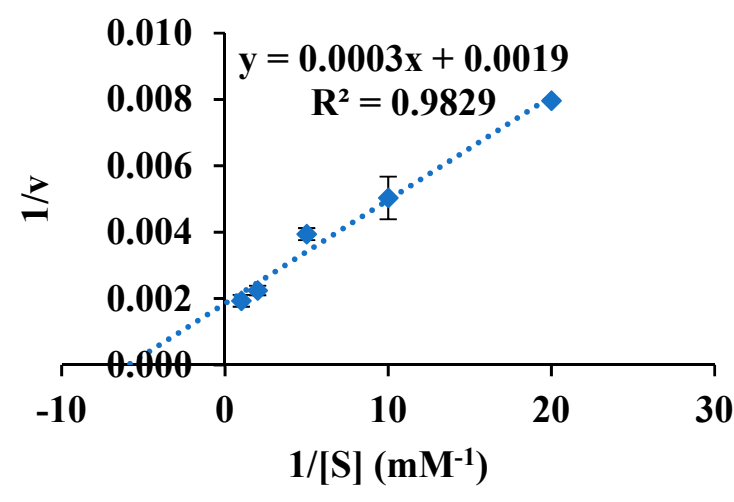

(a)

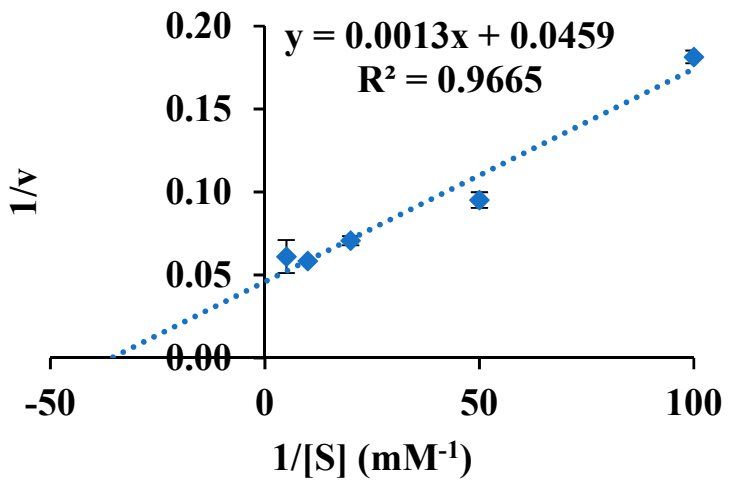

(b)

Figure 8. Lineweaver-Burk plots of Est8L (a) and Est13L (b) for pNPB. Five substrate concentrations were used; they were $0.05,0.10,0.20,0.50$, and $1.00 \mathrm{mM}$ for Est $8 \mathrm{~L}$, and $0.01,0.02,0.05,0.10$, and $0.20 \mathrm{mM}$ for Est13L.

Est8L was significantly inhibited to $22.64 \%, 2.44 \%$, and $1.76 \%$ by $30 \%$ methanol, isopropanol, and acetonitrile, respectively, and was moderately inhibited by $47.6 \%$ by $1 \%$ Triton-X 100 but was almost completely inhibited by $1 \%$ SDS (Figure 9a). Est13L was significantly activated to $356.1 \%$ by $30 \%$ methanol and to $182.9 \%$ by $30 \%$ isopropanol but was inhibited to $37 \%$ by $30 \%$ acetonitrile (Figure $9 \mathrm{~b}$ ). Est $13 \mathrm{~L}$ was inhibited to $14.0 \%$ by $1 \%$ SDS, but its activity remained at $82.4 \%$ by $1 \%$ Triton-X-100. Est $8 \mathrm{~L}$ and Est $13 \mathrm{~L}$ showed no significant inhibition at $1 \mathrm{mM}$ EDTA; however, both were strongly inhibited by $1 \mathrm{mM}$ PMSF with $2.87 \%$ and $6.45 \%$ activities, respectively, indicating both are serine esterases (Figure 9). 


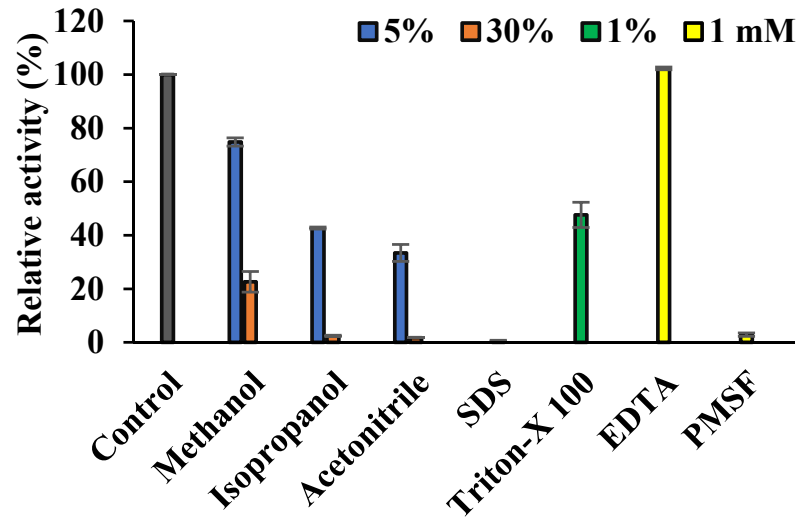

(a)

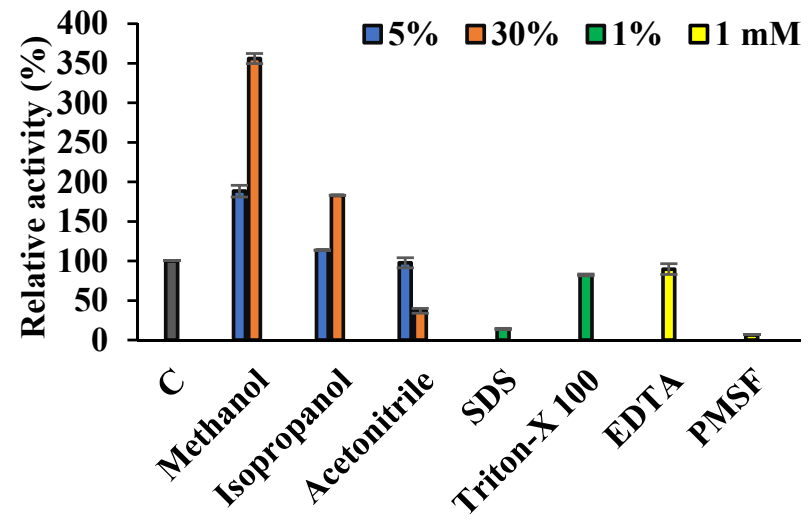

(b)

Figure 9. Effects of organic solvents, detergents, and inhibitors on the activities of Est8L (a) and Est13L (b). The activity was measured using an esterase assay with pNPB as a substrate.

Est8L was significantly inhibited to $0 \%, 13.2 \%$, and $29.0 \%$ at $5 \mathrm{mM} \mathrm{Cu}^{2+}, \mathrm{Zn}^{2+}$, and $\mathrm{Cu}^{2+}$, respectively, whereas Est13L was not significantly inhibited by most ions tested, except moderate inhibitions to $39.1 \%$ and $58.8 \%$ at $5 \mathrm{mM} \mathrm{Cu}^{2+}$ and $\mathrm{Zn}^{2+}$, respectively (Figure 10).

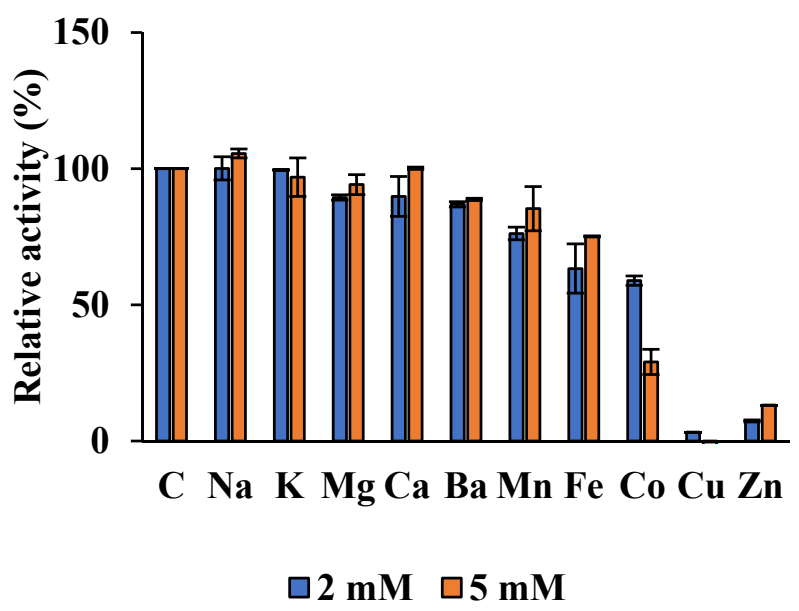

(a)

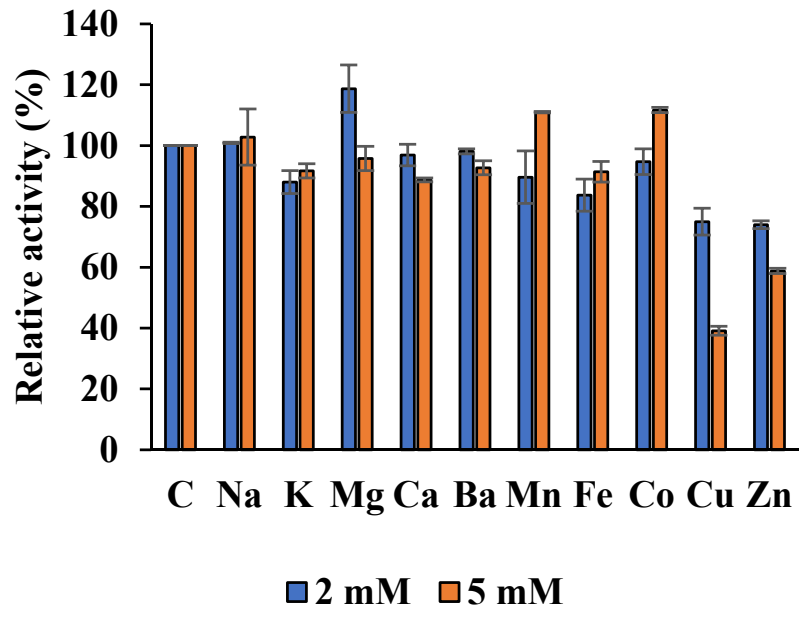

(b)

Figure 10. Effects of cations on activities of Es8L (a) and Est13L (b).

In the hydrolysis of glyceryl esters, Est8L and Est13L preferred glyceryl tributyrate (C4). After hydrolysis for 60 min under the condition described in Materials and Methods, Est8L and Est13L showed similar patterns for hydrolysis of glyceryl triesters and oils; for glyceryl tributyrate, they showed hydrolysis of $16.1 \%$ and $15.6 \%$, respectively, and for fish oil, they showed hydrolysis of $86.7 \%$ and $82.6 \%$, respectively. Both enzymes showed no significant activities with glyceryl trioleate (C18) and olive oil (Figure 11). 


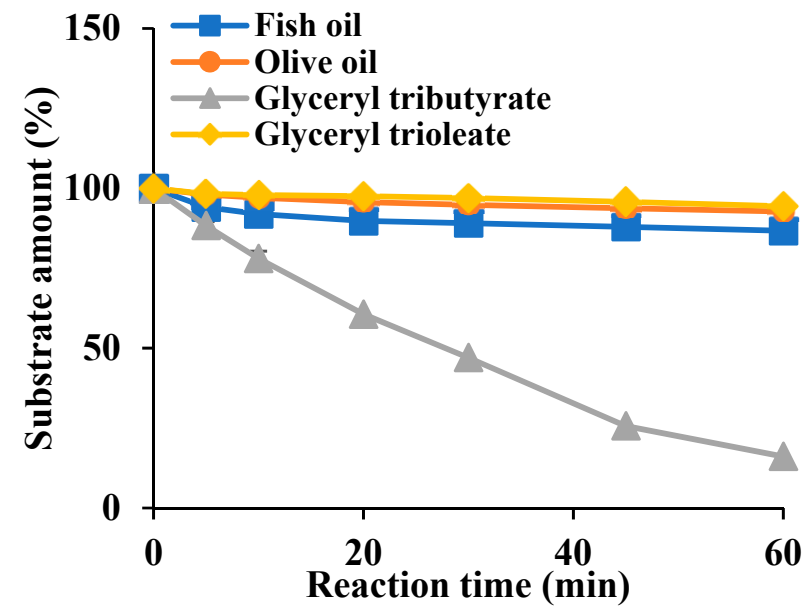

(a)

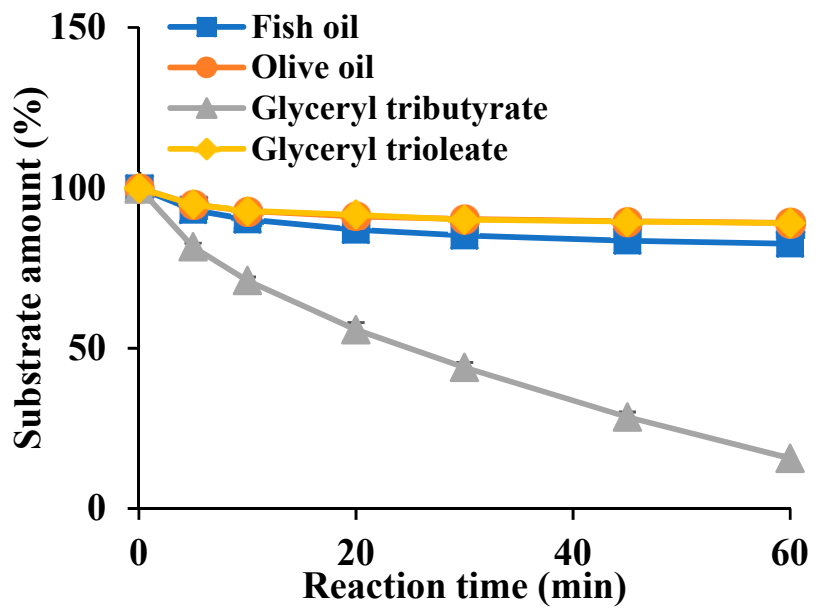

(b)

Figure 11. Lipid hydrolysis activities of Est8L (a) and Est13L (b).

In enantioselectivity, Est8L hydrolyzed the $S$-form with $10.1 \%$ higher activity than the $R$-form, suggesting preferences for the $S$-form, whereas Est13L showed no selectivity for the enantiomers (Figure 12). In the $t$-test, it was observed that the enantioselectivity for $S$-form was significant compared to $R$-form with a $p$-value $<0.05$.

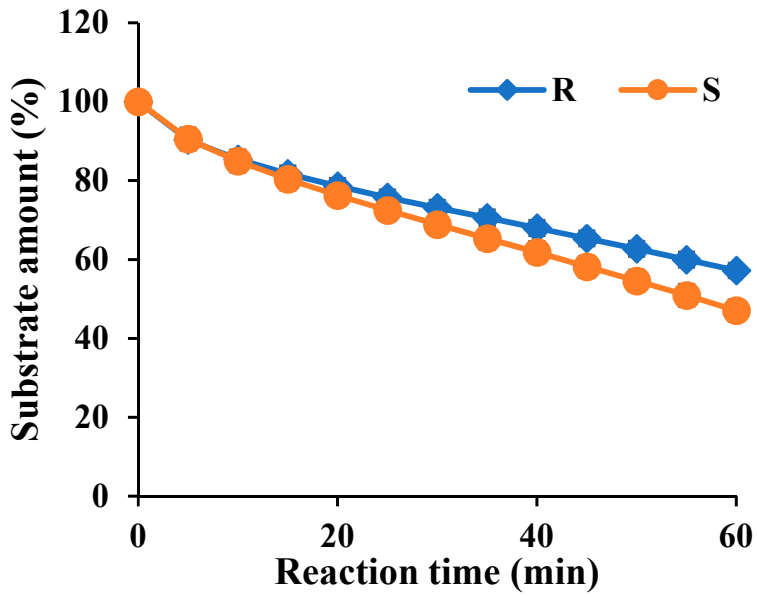

(a)

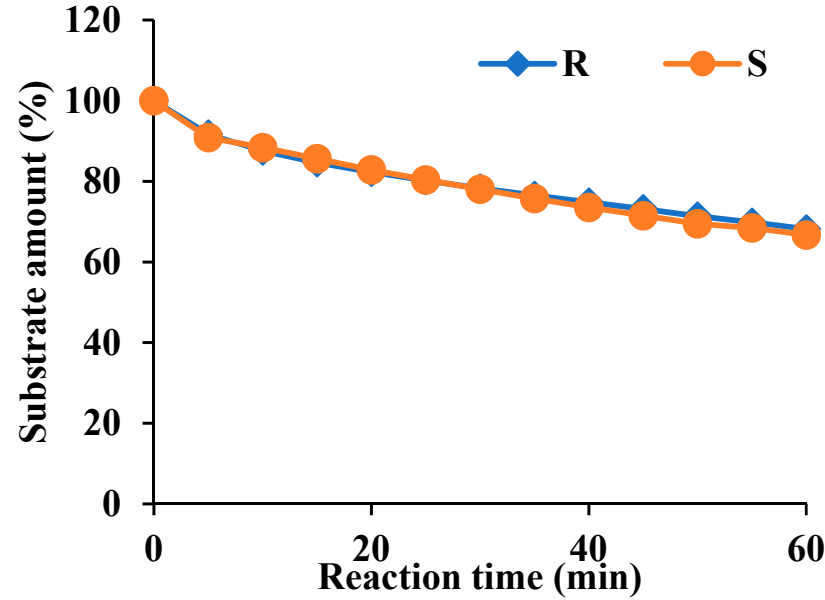

(b)

Figure 12. Enantioselectivities of Es8L (a) and Est13L (b).

\section{Discussion}

In this study, two novel esterases were characterized. Although the amino acid sequence of Est8L was the same as that of an esterase (MBF6602187) of a metagenome isolated from diarrhea-affected cattle $B$, the enzymatic properties have not been reported yet. Est8L has low identities $(10.7 \%-38.6 \%)$ to other characterized HSLs [33-37]. Est13L was very similar to Est7K, with an identity of $98.5 \%$, and its enzymatic properties were characterized [22]. Est13L was different from Est7K only in six residues, i.e., S36N, K107N, G220E, A236S, S250P, and D265E. However, the properties of Est13L were different from those of Est7K in substrate specificity (C6 vs. C4), enantioselectivity (non-selective vs. $S$-form selective), and effect by $\mathrm{Zn}^{2+}$ (inhibited vs. non-inhibited).

In comparison with family IV esterases from similar compost metagenomic sources, Est8L had poor organic solvents stabilities, whereas EstCs1 from a compost metagenomic 
library was stable at 30\% isopropanol, ethanol, acetonitrile, acetone, methanol, dimethyl formamide, and dimethyl sulfoxide [10]. In addition, Est8L was optimally active at $\mathrm{pH}$ 10.0, whereas EstCs1 was optimally active at $\mathrm{pH} 8.0$ [10].

In the case of family VIII esterases from similar compost metagenome, Est13L showed similar specific activity EstCs3 from a compost metagenomic library (42.3 vs. $50.2 \mathrm{U} / \mathrm{mg}$ ). On the other hand, Est13L was stable or activated under organic solvents, whereas EstCs3 was abolished or significantly inactivated by organic solvents such as $30 \%$ isopropanol, acetonitrile, ethanol, and methanol [11]. Est13L and EstCs3 showed similar molecular weights; however, their native forms were different (tetramer vs. monomer) [11].

To compare the properties of the Est8L and Est13L with each family, we searched the characterized enzymes at Pubmed (https:/ / pubmed.ncbi.nlm.nih.gov/, accessed on 25 May 2021). The summary of characterization of each enzyme-containing Est8L and Est13L were described (Tables 3 and 4). Family IV and VIII esterases have been practically interested in the usage of ester synthesis and transesterification reactions, and especially hydrolysis of antibiotics by family VIII [10,11].

Specific activities of Est8L and Est13L at the final purification step were 388.6 and $42.33 \mathrm{U} / \mathrm{mg}$, respectively. Est8L showed a higher specific activity than most family IV esterases such as Est2L (0.22 U/mg) [33], EstKT7 $(0.3 \mathrm{U} / \mathrm{mg})$ [38], Est4 $(0.64 \mathrm{U} / \mathrm{mg})$ [39], Rv0045c (3.5 U/mg) [40,41], Est3 (3.92 U/mg) [37], Est3K (8.4 U/mg) [18], EstZ (42 U/mg) [42], EstKT4 (237.9 U/mg) [38], and E40 (239.2 U/mg) [43,44], except EstKT9 (426.8 U/mg) [38], Est22 (2065 U/mg) [45], AFEST (3000 U/mg) [46,47], and PestE (3910 U/mg) [34,35]. In contrast, Est13L had a moderate specific activity compared to other family VIII esterases, which ranged from 6.7 to $1900 \mathrm{U} / \mathrm{mg}$ [48-50], and a significantly lower specific activity than Est7K (790.2 U/mg) [22], despite its high identity to Est7K.

The native form of Est8L was observed as a dimer, similar to other HSLs such as PestE [34,35] and Est22 [45] (Table 3). The native form of Est13L was a tetramer, which was unique and unlikely the other family VIII esterases; most family VIII esterases are monomers in their native forms, such as EstC [49], EstBL [51], EstCE1 [52], EstIII [53], and EstCS3 [11]. Est22 was a trimer in its native form [54], and EstA3 required an oligomeric form containing less than six subunits for activation [52] (Table 4).

Est8L and Est13L are alkaline esterases. The optimum pH range of bHSLs is broad, from 5.0 to 9.0. In contrast, the optimum $\mathrm{pH}$ range of most family VIII esterases ranges from 7.2 to 10.0, indicating that most family VIII esterases are alkaline esterases. Only a few family VIII esterases have been reported as neutral esterases, the optimum $\mathrm{pH}$ of which is 7.0, such as LipBL [55], EstB [56], Lpc53E1 [50], and Lip8 [57] (Tables 3 and 4).

The optimum temperature $\left(40^{\circ} \mathrm{C}\right)$ of Est8L was similar to that of most bHSLs, which are optimally active at $30-50{ }^{\circ} \mathrm{C}$, except a few cases such as EstE1 $\left(90{ }^{\circ} \mathrm{C}\right)$ [58], PestE $\left(90^{\circ} \mathrm{C}\right)[34,35]$, EST2 $\left(70{ }^{\circ} \mathrm{C}\right)[59]$, and SaHSL $\left(70{ }^{\circ} \mathrm{C}\right)$ [60]. The optimum temperature of family VIII esterases was also distributed from 30 to $50^{\circ} \mathrm{C}$, except LipBL $\left(80^{\circ} \mathrm{C}\right)$ [55] and LipA9 $\left(70{ }^{\circ} \mathrm{C}\right)$ [61] (Tables 3 and 4). From these results, it could be considered that the optimum temperature $\left(40^{\circ} \mathrm{C}\right)$ for Est8L and Est $13 \mathrm{~L}$ is the average of their family members.

The substrate specificity of bHSLs for pNP esters ranged from $\mathrm{C} 2$ to $\mathrm{C} 6$, with the most preferred substrates being C2 and C4. Most family VIII esterases prefer C4, likely Est7K [22], which showed the highest identity (98.5\%) to Est13L. However, Est13L preferred $\mathrm{C} 6$, although the degree was similar to $\mathrm{C} 4$ and $\mathrm{C} 8$ with broad specificity. Some family VIII esterases prefer C6, such as LipA9 [61], LipBL [55], and DLFae4 [62] (Tables 3 and 4).

Est8L is sensitive to isopropanol and acetonitrile, similar to Est22 [45], which is inhibited to $40 \%$ and $0 \%$, respectively, by $30 \%$ isopropanol and acetonitrile. Most reported bHSL family members exhibit poor stabilities for organic solvents such as DMWf18-543, DMwf18-558 [17], Est3 [37], and E69 [63]. In contrast, PestE shows suitable stability under organic solvents, maintaining its activity at $\sim 100 \%[34,35]$. Similar stability was reported at EstCS1 [10] (Table 3). However, Est13L was resistant to or activated in organic solvents under $30 \%$ isopropanol or methanol to $183 \%$ or $356 \%$, respectively, similar to Est7K [22] but to a greater extent. Similar activations were reported for EstA3 [52], LPC53E1 [50], and 
EstC [49], which were activated by alcohol solvents. Most family VIII esterases, including Est13L, were inhibited by acetonitrile, but Lpc53E1 was extremely activated to $271.2 \%$ under $20 \%$ acetonitrile [50] (Table 4 ).

Est8L showed enantioselectivity for the $S$-form, whereas some bHSLs showed enantioselectivity for the $R$-form, such as EST2 [59] and PestE [34,35] (Table 3). Est13L showed no enantioselectivity, whereas Est7K [22] showed enantioselectivity for the $S$-form, although their sequences were very similar. In family VIII esterases, EstF4k showed enantioselectivity for $R$-form methyl 3-phenylglycidate [64], and EstA3 was highly enantioselective for $S$-form enantiomers [52] (Table 4).

In terms of the ion effects, Est8L showed an inhibition tendency as the metal ion group increased, with moderate inhibition by $\mathrm{Co}^{2+}$ and significant inhibitions by $\mathrm{Cu}^{2+}$ and $\mathrm{Zn}^{2+}$. Similar patterns were reported for other bHSLs such as Est22 [45], SaestA [65], Est4 [39], EstKT7 [35], DMWf18-543, and DMWf18-558 [17] with significant inhibition by $\mathrm{Cu}^{2+}$ and $\mathrm{Zn}^{2+}$ (Table 3). However, Est13L showed higher stability on metal ions than Est8L, but its pattern was similar, and it was slightly inhibited by $\mathrm{Cu}^{2+}$ and $\mathrm{Zn}^{2+}$. In family VIII, EstA3 [52] and EstM-N2 [66] were also inhibited by $\mathrm{Cu}^{2+}$ and $\mathrm{Zn}^{2+}$ (Table 4).

Collectively, Est8L showed a low identity and a higher specific activity than most other family IV esterases reported and different properties in enantioselectivity and sensitivity to the internal proteolytic activity. In contrast, Est13L showed different properties in terms of substrate specificity, specific activity, enantioselectivity, and metal ion inhibition compared to Est7K, although both differed in only six amino acids, similar to the reports that one or several amino acids could cause changes in enzyme properties such as specific activities, substrates specificities, thermostabilities, solvent tolerances, and stereoselectivities in esterases and lipases [67-71]. 
Table 3. Comparison of Est8L and other bacterial hormone-sensitive lipases (bHSLs).

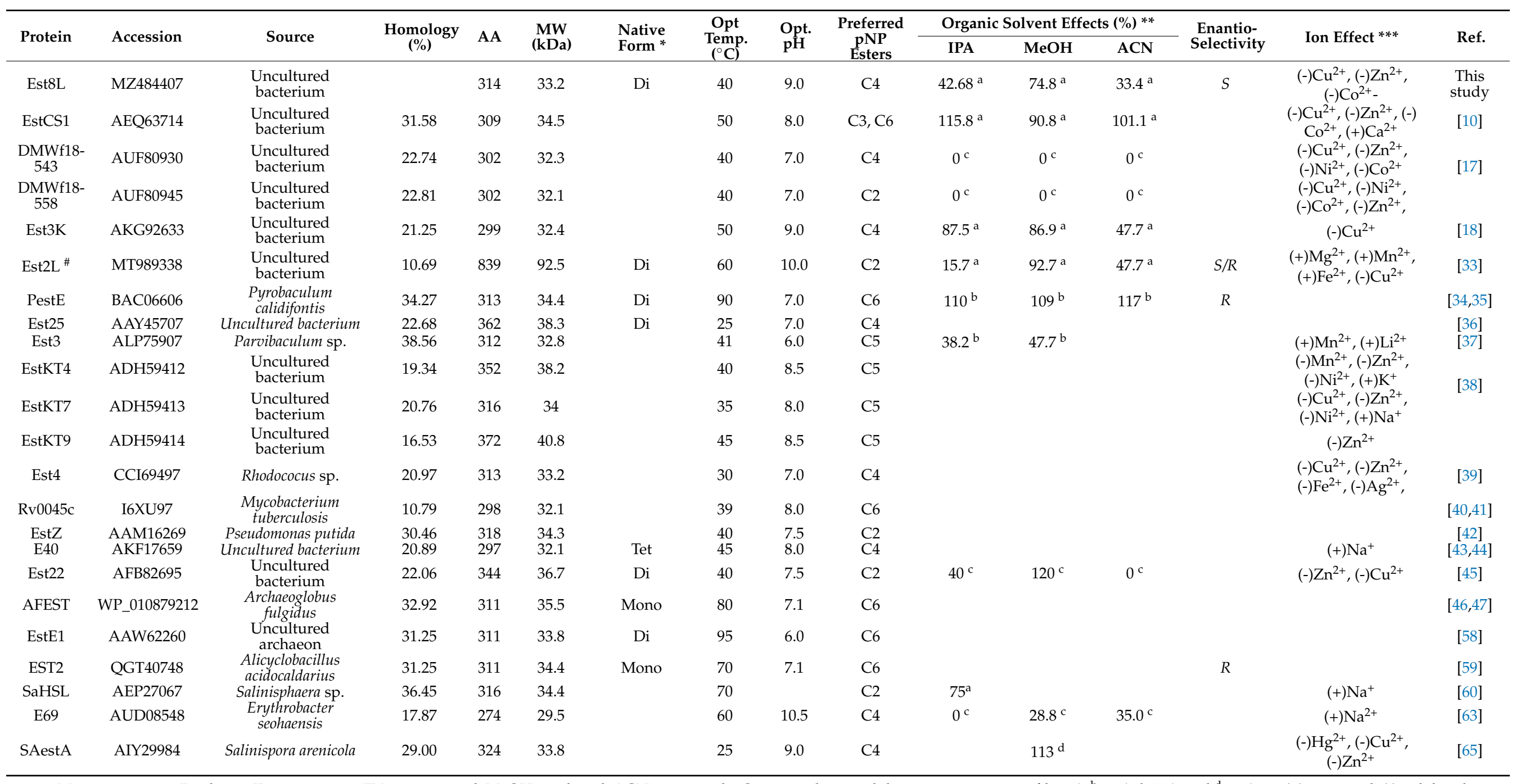

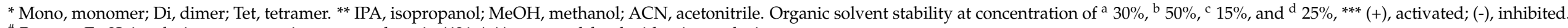

\# Because Est2L is a fusion-type protein, esterase domain (421 AA) was used for the identity analysis. 
Table 4. Comparison of Est13L and other family VIII esterases.

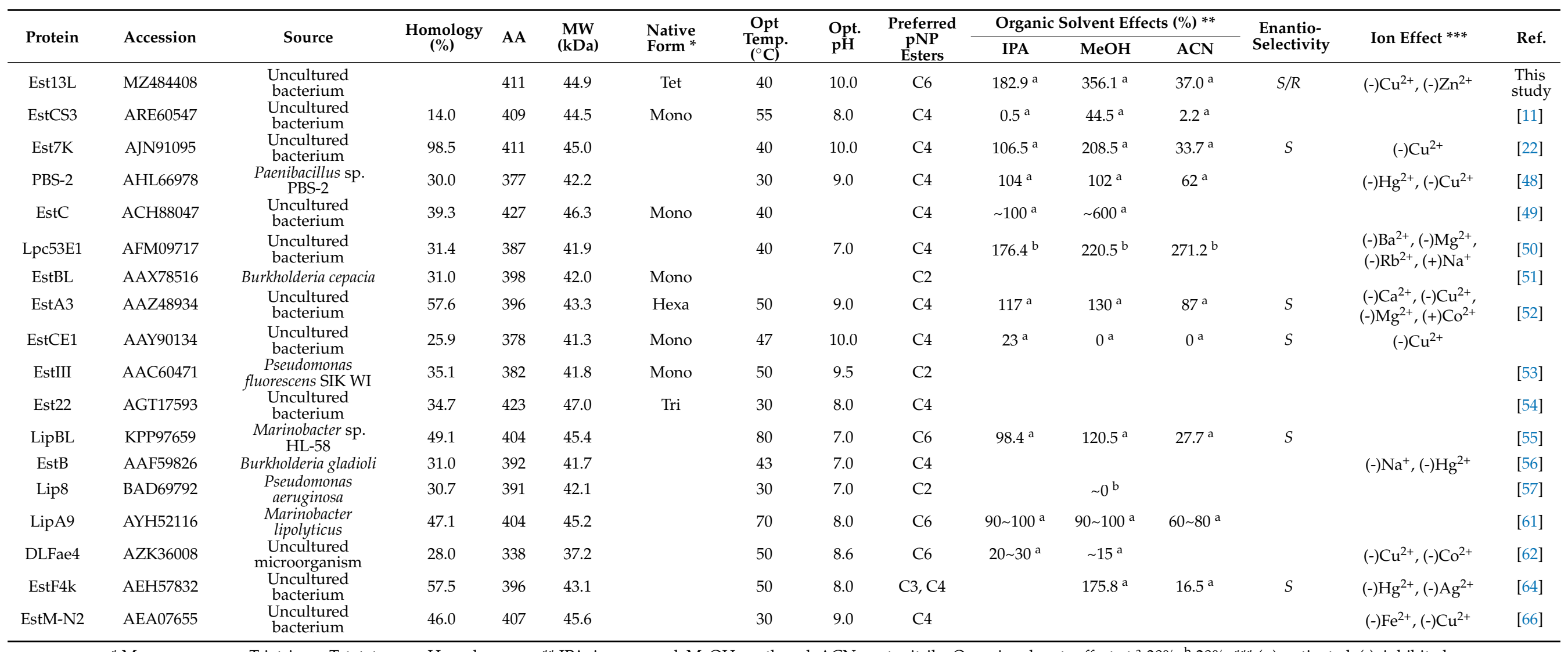

${ }^{*}$ Mono, monomer; Tri, trimer; Tet, tetramer; Hexa, hexamer. ${ }^{* *} \mathrm{IPA}$, isopropanol; MeOH, methanol; ACN, acetonitrile. Organic solvents effect at ${ }^{\text {a } 30 \%,}$, $20 \%$. ${ }^{* * *}(+)$, activated; $(-)$, inhibited. 


\section{Conclusions}

In this study, two novel esterase genes est8L and est13L encoding intracellular Est8L and Est13L, respectively, were isolated from the compost metagenomic library. Est8L and $13 \mathrm{~L}$ were revealed to be novel members of family IV esterase (bHSL) and family VIII esterase, respectively. Est8L had similar characteristics to bHSL, such as substrate specificity for $\mathrm{C} 4$ and optimum temperature and $\mathrm{pH}$ values of $40^{\circ} \mathrm{C}$ and 9.0 , respectively. Est8L exhibited enantioselectivity for the $S$-form (10.16\% higher than the $R$-form). Est13L also had similar characteristics such as molecular weight and optimum temperature and $\mathrm{pH}$. However, Est13L was a tetramer in its native form; unlikely, other family VIII esterases were reported. Est8L was sensitive to isopropanol and acetonitrile, whereas Est13L was activated by $30 \%$ isopropanol or methanol. In contrast, Est8L and Est13L were inhibited by $\mathrm{Cu}^{2+}$ and $\mathrm{Zn}^{2+}$ with similar patterns, but Est13L was more stable than Est8L. In conclusion, Est8L had higher specific activity than most of other HSLs and enantioselectivity for the $S$-form; however, it was sensitive to organic solvents; Est13L had higher stability against ions, organic solvents such as alcoholic solvents (isopropanol and methanol), unusual tetrameric form in family VIII esterases, and thermal stress. These results suggested that Est8L and Est13L can be used for chemical reactions with enantioselectivity and for detergent/chemical reactions under alkaline conditions, respectively.

Supplementary Materials: The following are available online at https:/ /www.mdpi.com/article/10 .3390/microorganisms9081614/s1.

Author Contributions: Conceptualization, H.K.; cloning, H.-W.L.; purification, G.-S.J. and J.-E.P.; analysis of enzymatic property, G.-S.J. and J.-E.P.; data curation, J.-E.P.; writing-original draft preparation, J.-E.P.; writing-review and editing, H.K; supervision, H.K. All authors have read and agreed to the published version of the manuscript.

Funding: This research received no external funding.

Institutional Review Board Statement: Not applicable.

Informed Consent Statement: Not applicable.

Data Availability Statement: The data presented in this study are available on request from the corresponding author.

Conflicts of Interest: The authors declare no conflict of interest.

\section{References}

1. Arpigny, J.L.; Jaeger, K.E. Bacterial lipolytic enzymes: Classification and properties. Biochem. J. 1999, 343, 177-183. [CrossRef]

2. Gudiukaite, R.; Gricajeva, A. Microbial lipolytic fusion enzymes: Current state and future perspectives. World J. Microbiol. Biotechnol. 2017, 33, 216. [CrossRef] [PubMed]

3. Priyanka, P.; Tan, Y.; Kinsella, G.K.; Henehan, G.T.; Ryan, B.J. Solvent stable microbial lipases: Current understanding and biotechnological applications. Biotechnol. Lett. 2019, 41, 203-220. [CrossRef]

4. Larsen, E.M.; Johnson, R.J. Microbial esterases and ester prodrugs: An unlikely marriage for combating antibiotic resistance. Drug Dev. Res. 2019, 80, 33-47. [CrossRef]

5. Parapouli, M.; Foukis, A.; Stergiou, P.Y.; Koukouritaki, M.; Magklaras, P.; Gkini, O.A.; Papamichael, E.M.; Afendra, A.S.; Hatziloukas, E. Molecular, biochemical and kinetic analysis of a novel, thermostable lipase (LipSm) from Stenotrophomonas maltophilia Psi-1, the first member of a new bacterial lipase family (XVIII). J. Biol. Res. Thessalon. 2018, 25, 4, reprinted in J. Biol. Res. Thessalon. 2018, 25, 10. [CrossRef]

6. Hong, K.H.; Jang, W.H.; Choi, K.D.; Yoo, O.J. Characterization of Pseudomonas fluorescens carboxylesterase: Cloning and expression of the esterase gene in Escherichia coli. Agric. Biol. Chem. 1991, 55, 2839-2845. [CrossRef] [PubMed]

7. Ollis, D.L.; Cheah, E.; Cygler, M.; Dijkstra, B.; Frolow, F.; Franken, S.M.; Harel, M.; Remington, S.J.; Silman, I.; Schrag, J. The alpha/beta hydrolase fold. Protein Eng. 1992, 5, 197-211. [CrossRef]

8. Höppner, A.; Bollinger, A.; Kobus, S.; Thies, S.; Coscolín, C.; Ferrer, M.; Jaeger, K.E.; Smits, S. Crystal structures of a novel family IV esterase in free and substrate-bound form. FEBS J. 2021, 288, 3570-3584. [CrossRef]

9. Schütte, M.; Fetzner, S. EstA from Arthrobacter nitroguajacolicus Rü61a, a thermo- and solvent-tolerant carboxylesterase related to class C beta-lactamases. Curr. Microbiol. 2007, 54, 230-236. [CrossRef]

10. Park, J.M.; Kang, C.H.; Won, S.M.; Oh, K.H.; Yoon, J.H. Characterization of a novel moderately thermophilic solvent-tolerant esterase isolated from a compost metagenome library. Front. Microbiol. 2020, 10, 3069. [CrossRef] [PubMed] 
11. Park, J.M.; Won, S.M.; Kang, C.H.; Park, S.; Yoon, J.H. Characterization of a novel carboxylesterase belonging to family VIII hydrolyzing $\beta$-lactam antibiotics from a compost metagenomic library. Int. J. Biol. Macromol. 2020, 164, 4650-4661. [CrossRef] [PubMed]

12. Handelsman, J.; Rondon, M.R.; Brady, S.F.; Clardy, J.; Goodman, R.M. Molecular biological access to the chemistry of unknown soil microbes: A new frontier for natural products. Chem. Biol. 1998, 5, R245-R249. [CrossRef]

13. Ogram, A.; Sayler, G.S.; Barkay, T. The extraction and purification of microbial DNA from sediments. J. Microbiol. Methods. 1987, 7, 57-66. [CrossRef]

14. Rondon, M.R.; August, P.R.; Bettermann, A.D.; Brady, S.F.; Grossman, T.H.; Liles, M.R.; Loiacono, K.A.; Lynch, B.A.; MacNeil, I.A.; Minor, C.; et al. Cloning the soil metagenome: A strategy for accessing the genetic and functional diversity of uncultured microorganisms. Appl. Environ. Microbiol. 2000, 66, 2541-2547. [CrossRef] [PubMed]

15. Taberlet, P.; Coissac, E.; Hajibabaei, M.; Rieseberg, L.H. Environmental DNA. Mol. Ecol. 2012, 21, 1789-1793. [CrossRef] [PubMed]

16. Oh, H.N.; Park, D.; Seong, H.J.; Kim, D.; Sul, W.J. Antarctic tundra soil metagenome as useful natural resources of cold-active lignocelluolytic enzymes. J. Microbiol. 2019, 57, 865-873. [CrossRef] [PubMed]

17. Huo, Y.Y.; Jian, S.L.; Cheng, H.; Rong, Z.; Cui, H.L.; Xu, X.W. Two novel deep-sea sediment metagenome-derived esterases: Residue 199 is the determinant of substrate specificity and preference. Microb. Cell Fact. 2018, 17, 16. [CrossRef]

18. Kim, H.J.; Jeong, Y.S.; Jung, W.K.; Kim, S.K.; Lee, H.W.; Kahng, H.Y.; Kim, J.; Kim, H. Characterization of novel family IV esterase and family I.3 lipase from an oil-polluted mud flat metagenome. Mol. Biotechnol. 2015, 7, 781-792. [CrossRef] [PubMed]

19. Angelov, A.; Pham, V.; Übelacker, M.; Brady, S.; Leis, B.; Pill, N.; Brolle, J.; Mechelke, M.; Moerch, M.; Henrissat, B.; et al. A metagenome-derived thermostable $\beta$-glucanase with an unusual module architecture which defines the new glycoside hydrolase family GH148. Sci. Rep. 2017, 7, 17306. [CrossRef] [PubMed]

20. Kim, Y.H.; Kwon, E.J.; Kim, S.K.; Jeong, Y.S.; Kim, J.; Yun, H.D.; Kim, H. Molecular cloning and characterization of a novel family VIII alkaline esterase from a compost metagenomic library. Biochem. Biophys. Res. Commun. 2010, 393, 45-49. [CrossRef]

21. Tiquia, S.M. Evolution of extracellular enzyme activities during manure composting. J. Appl. Microbiol. 2002, 92, 764-775. [CrossRef]

22. Lee, H.W.; Jung, W.K.; Kim, Y.H.; Ryu, B.H.; Kim, T.D.; Kim, J.; Kim, H. Characterization of a novel alkaline family VIII esterase with S-enantiomer Preference from a compost metagenomic library. J. Microbiol. Biotechnol. 2016, 26, 315-325. [CrossRef]

23. Kumar, S.; Stecher, G.; Li, M.; Knyaz, C.; Tamura, K. MEGA X: Molecular evolutionary genetics analysis across computing platforms. Mol. Biol. Evol. 2018, 35, 1547-1549. [CrossRef] [PubMed]

24. Laemmli, U.K. Cleavage of structural proteins during the assembly of the head of bacteriophage T4. Nature 1970, 227, 680-685. [CrossRef] [PubMed]

25. Bradford, M.M. A rapid and sensitive method for the quantitation of microgram quantities of protein utilizing the principle of protein-dye binding. Anal. Biochem. 1976, 72, 248-254. [CrossRef]

26. Lee, J.P.; Kang, M.G.; Lee, J.Y.; Oh, J.M.; Baek, S.C.; Leem, H.H.; Park, D.; Cho, M.L.; Kim, H. Potent inhibition of acetylcholinesterase by sargachromanol I from Sargassum siliquastrum and by selected natural compounds. Bioorg. Chem. 2019, 89, 103043. [CrossRef] [PubMed]

27. Ngo, T.D.; Ryu, B.H.; Ju, H.; Jang, E.J.; Kim, K.K.; Kim, T.D. Crystallographic analysis and biochemical applications of a novel penicillin-binding protein/ $\beta$-lactamase homologue from a metagenomic library. Acta Crystallogr. D. Biol. Crystallogr. 2014, 70, 2455-2466. [CrossRef]

28. Lee, J.P.; Kim, Y.A.; Kim, S.K.; Kim, H. Characterization of a multimodular endo- $\beta-1,4-$ glucanase (Cel9K) from Paenibacillus sp. X4 with a potential additive for saccharification. J. Microbiol. Biotechnol. 2018, 28, 588-596. [CrossRef]

29. Jung, K.H.; Lee, K.M.; Kim, H.; Yoon, K.H.; Park, S.H.; Pack, M.Y. Cloning and expression of a Clostridium thermocellum xylanase gene in Escherichia coli. Biochem. Mol. Biol. Int. 1998, 44, 283-292. [CrossRef]

30. Feng, J.X.; Karita, S.; Fujino, E.; Fujino, T.; Kimura, T.; Sakka, K.; Ohmiya, K. Cloning, sequencing, and expression of the gene encoding a cell-bound multi-domain xylanase from Clostridium josui, and characterization of the translated product. Biosci. Biotechnol. Biochem. 2000, 64, 2614-2624. [CrossRef]

31. Pastor, F.I.; Pujol, X.; Blanco, A.; Vidal, T.; Torres, A.L.; Díaz, P. Molecular cloning and characterization of a multidomain endoglucanase from Paenibacillus sp BP-23: Evaluation of its performance in pulp refining. Appl. Microbiol. Biotechnol. 2001, 55, 61-68. [CrossRef] [PubMed]

32. Lee, J.P.; Lee, H.W.; Na, H.B.; Lee, J.H.; Hong, Y.J.; Jeon, J.M.; Kwon, E.J.; Kim, S.K.; Kim, H. Characterization of truncated endo- $\beta-1,4-$ glucanases from a compost metagenomic library and their saccharification potentials. Int. J. Biol. Macromol. 2018, 115, 554-562. [CrossRef] [PubMed]

33. Park, J.E.; Jeong, G.S.; Lee, H.W.; Kim, S.K.; Kim, J.; Kim, H. Characterization of a novel family IV esterase containing a predicted $\mathrm{CzcO}$ domain and a family $\mathrm{V}$ esterase with broad substrate specificity from an oil-polluted mud flat metagenomic library. Appl. Sci. 2021, 11, 5905. [CrossRef]

34. Hotta, Y.; Ezaki, S.; Atomi, H.; Imanaka, T. Extremely stable and versatile carboxylesterase from a hyperthermophilic archaeon. Appl. Environ. Microbiol. 2002, 68, 3925-3931. [CrossRef] [PubMed]

35. Benavente, R.; Esteban-Torres, M.; Acebrón, I.; de Las Rivas, B.; Muñoz, R.; Alvarez, Y.; Mancheño, J.M. Structure, biochemical characterization and analysis of the pleomorphism of carboxylesterase Cest-2923 from Lactobacillus plantarum WCFS1. FEBS J. 2013, 280, 6658-6671. [CrossRef] 
36. Ngo, T.D.; Ryu, B.H.; Ju, H.; Jang, E.; Park, K.; Kim, K.K.; Kim, T.D. Structural and functional analyses of a bacterial homologue of hormone-sensitive lipase from a metagenomic library. Acta Crystallogr. D Biol. Crystallogr. 2013, 69, 1726-1737. [CrossRef] [PubMed]

37. Maester, T.C.; Pereira, M.R.; Machado Sierra, E.G.; Balan, A.; de Macedo Lemos, E.G. Characterization of EST3: A metagenomederived esterase with suitable properties for biotechnological applications. Appl. Microbiol. Biotechnol. 2016, 100, 5815-5827. [CrossRef]

38. Jeon, J.H.; Lee, H.S.; Kim, J.T.; Kim, S.J.; Choi, S.H.; Kang, S.G.; Lee, J.H. Identification of a new subfamily of salt-tolerant esterases from a metagenomic library of tidal flat sediment. Appl. Microbiol. Biotechnol. 2012, 93, 623-631. [CrossRef]

39. Bassegoda, A.; Fillat, A.; Pastor, F.I.; Diaz, P. Special Rhodococcus sp. CR-53 esterase Est4 contains a GGG(A)X-oxyanion hole conferring activity for the kinetic resolution of tertiary alcohols. Appl. Microbiol. Biotechnol. 2013, 97, 8559-8568. [CrossRef] [PubMed]

40. Guo, J.; Zheng, X.; Xu, L.; Liu, Z.; Xu, K.; Li, S.; Wen, T.; Liu, S.; Pang, H. Characterization of a novel esterase Rv0045c from Mycobacterium tuberculosis. PLoS ONE 2010, 5, e13143. [CrossRef]

41. Zheng, X.; Guo, J.; Xu, L.; Li, H.; Zhang, D.; Zhang, K.; Sun, F.; Wen, T.; Liu, S.; Pang, H. Crystal structure of a novel esterase Rv0045c from Mycobacterium tuberculosis. PLoS ONE 2011, 6, e20506. [CrossRef] [PubMed]

42. Hasona, A.; York, S.W.; Yomano, L.P.; Ingram, L.O.; Shanmugam, K.T. Decreasing the level of ethyl acetate in ethanolic fermentation broths of Escherichia coli KO11 by expression of Pseudomonas putida estZ esterase. Appl. Environ. Microbiol. 2002, 68, 2651-2659. [CrossRef] [PubMed]

43. Li, P.Y.; Zhang, Y.; Xie, B.B.; Zhang, Y.Q.; Hao, J.; Wang, Y.; Wang, P.; Li, C.Y.; Qin, Q.L.; Zhang, X.Y.; et al. Structural and mechanistic insights into the improvement of the halotolerance of a marine microbial esterase by increasing intra- and interdomain hydrophobic interactions. Appl. Environ. Microbiol. 2017, 83, e01286-17. [CrossRef]

44. Li, P.Y.; Chen, X.L.; Ji, P.; Li, C.Y.; Wang, P.; Zhang, Y.; Xie, B.B.; Qin, Q.L.; Su, H.N.; Zhou, B.C.; et al. Interdomain hydrophobic interactions modulate the thermostability of microbial esterases from the hormone-sensitive lipase family. J. Biol. Chem. 2015, 290, 11188-11198. [CrossRef]

45. Huang, J.; Huo, Y.Y.; Ji, R.; Kuang, S.; Ji, C.; Xu, X.W.; Li, J. Structural insights of a hormone sensitive lipase homologue Est22. Sci. Rep. 2016, 6, 28550. [CrossRef]

46. De Simone, G.; Menchise, V.; Manco, G.; Mandrich, L.; Sorrentino, N.; Lang, D.; Rossi, M.; Pedone, C. The crystal structure of a hyper-thermophilic carboxylesterase from the archaeon Archaeoglobus fulgidus. J. Mol. Biol. 2001, 314, 507-518. [CrossRef]

47. Manco, G.; Giosuè, E.; D'Auria, S.; Herman, P.; Carrea, G.; Rossi, M. Cloning, overexpression, and properties of a new thermophilic and thermostable esterase with sequence similarity to hormone-sensitive lipase subfamily from the archaeon Archaeoglobus fulgidus. Arch. Biochem. Biophys. 2000, 373, 182-192. [CrossRef]

48. Rashamuse, K.; Magomani, V.; Ronneburg, T.; Brady, D. A novel family VIII carboxylesterase derived from a leachate metagenome library exhibits promiscuous beta-lactamase activity on nitrocefin. Appl. Microbiol. Biotechnol. 2009, 83, 491-500. [CrossRef] [PubMed]

49. Kim, Y.O.; Park, I.S.; Nam, B.H.; Kim, D.G.; Jee, Y.J.; Lee, S.J.; An, C.M. A novel esterase from Paenibacillus sp. PBS-2 is a new member of the $\beta$-lactamase belonging to the family VIII lipases/esterases. J. Microbiol. Biotechnol. 2014, 24, 1260-1268. [CrossRef]

50. Selvin, J.; Kennedy, J.; Lejon, D.P.; Kiran, G.S.; Dobson, A.D. Isolation identification and biochemical characterization of a novel halo-tolerant lipase from the metagenome of the marine sponge Haliclona simulans. Microb. Cell Fact. 2012, 11, 72. [CrossRef]

51. Rashamuse, K.J.; Burton, S.G.; Stafford, W.H.; Cowan, D.A. Molecular characterization of a novel family VIII esterase from Burkholderia multivorans UWC10. J. Mol. Microbiol. Biotechnol. 2007, 13, 181-188. [CrossRef] [PubMed]

52. Elend, C.; Schmeisser, C.; Leggewie, C.; Babiak, P.; Carballeira, J.D.; Steele, H.L.; Reymond, J.L.; Jaeger, K.E.; Streit, W.R. Isolation and biochemical characterization of two novel metagenome-derived esterases. Appl. Environ. Microbiol. 2006, 72, 3637-3645. [CrossRef]

53. Kim, Y.S.; Lee, H.B.; Choi, K.D.; Park, S.; Yoo, O.J. Cloning of Pseudomonas fluorescens carboxylesterase gene and characterization of its product expressed in Escherichia coli. Biosci. Biotechnol. Biochem. 1994, 58, 111-116. [CrossRef] [PubMed]

54. Mokoena, N.; Mathiba, K.; Tsekoa, T.; Steenkamp, P.; Rashamuse, K. Functional characterisation of a metagenome derived family VIII esterase with a deacetylation activity on $\beta$-lactam antibiotics. Biochem. Biophys. Res. Commun. 2013, 437, 342-348. [CrossRef]

55. Pérez, D.; Martín, S.; Fernández-Lorente, G.; Filice, M.; Guisán, J.M.; Ventosa, A.; García, M.T.; Mellado, E. A novel halophilic lipase, LipBL, showing high efficiency in the production of eicosapentaenoic acid (EPA). PLoS ONE 2011, 6, e23325. [CrossRef]

56. Petersen, E.I.; Valinger, G.; Sölkner, B.; Stubenrauch, G.; Schwab, H. A novel esterase from Burkholderia gladioli which shows high deacetylation activity on cephalosporins is related to beta-lactamases and DD-peptidases. J. Biotechnol. 2001, 89, 11-25. [CrossRef]

57. Ogino, H.; Mimitsuka, T.; Muto, T.; Matsumura, M.; Yasuda, M.; Ishimi, K.; Ishikawa, H. Cloning, expression, and characterization of a lipolytic enzyme gene (lip8) from Pseudomonas aeruginosa LST-03. J. Mol. Microbiol. Biotechnol. 2004, 7, 212-223. [CrossRef]

58. Byun, J.S.; Rhee, J.K.; Kim, N.D.; Yoon, J.; Kim, D.U.; Koh, E.; Oh, J.W.; Cho, H.S. Crystal structure of hyperthermophilic esterase EstE1 and the relationship between its dimerization and thermostability properties. BMC Struct. Biol. 2007, 7, 47. [CrossRef]

59. De Simone, G.; Galdiero, S.; Manco, G.; Lang, D.; Rossi, M.; Pedone, C. A snapshot of a transition state analogue of a novel thermophilic esterase belonging to the subfamily of mammalian hormone-sensitive lipase. J. Mol. Biol. 2000, 303, 761-771. [CrossRef] 
60. Kim, B.Y.; Yoo, W.; Luu Le, L.T.H.; Kim, K.K.; Kim, H.W.; Lee, J.H.; Kim, Y.O.; Kim, T.D. Characterization and mutation anaylsis of a cold-active bacterial hormone-sensitive lipase from Salinisphaera sp. P7-4. Arch. Biochem. Biophys. 2019, 15, 132-142. [CrossRef] [PubMed]

61. Park, S.H.; Kim, S.J.; Park, S.; Kim, H.K. Characterization of organic solvent-tolerant lipolytic enzyme from Marinobacter lipolyticus isolated from the antarctic ocean. Appl. Biochem. Biotechnol. 2019, 187, 1046-1060. [CrossRef] [PubMed]

62. Nan, F.; Jiang, J.; Wu, S.; Zhang, Y.; Qiu, J.; Qiao, B.; Li, S.; Xin, Z. A novel VIII carboxylesterase with high hydrolytic activity against ampicillin from a soil metagenomic library. Mol. Biotechnol. 2019, 61, 892-904. [CrossRef]

63. Huo, Y.Y.; Rong, Z.; Jian, S.L.; Xu, C.D.; Li, J.; Xu, X.W. A novel halotolerant thermoalkaliphilic esterase from marine bacterium Erythrobacter seohaensis SW-135. Front. Microbiol. 2017, 22, 2315. [CrossRef] [PubMed]

64. Ouyang, L.M.; Liu, J.Y.; Qiao, M.; Xu, J.H. Isolation and biochemical characterization of two novel metagenome-derived esterases. Appl. Biochem. Biotechnol. 2013, 169, 15-28. [CrossRef] [PubMed]

65. Fang, Y.; Wang, S.; Liu, S.; Jiao, Y. Discovery a novel organic solvent tolerant esterase from Salinispora arenicola CNP193 through genome mining. Int. J. Biol. Macromol. 2015, 80, 334-340. [CrossRef]

66. Yu, E.Y.; Kwon, M.A.; Lee, M.; Oh, J.Y.; Choi, J.E.; Lee, J.Y.; Song, B.K.; Hahm, D.H.; Song, J.K. Isolation and characterization of cold-active family VIII esterases from an arctic soil metagenome. Appl. Microbiol. Biotechnol. 2011, 90, 573-581. [CrossRef] [PubMed]

67. Akbulut, N.; Tuzlakoğlu Öztürk, M.; Pijning, T.; İşsever Öztürk, S.; Gümüşel, F. Improved activity and thermostability of Bacillus pumilus lipase by directed evolution. J. Biotechnol. 2013, 164, 123-129. [CrossRef] [PubMed]

68. Van Pouderoyen, G.; Eggert, T.; Jaeger, K.E.; Dijkstra, B.W. The crystal structure of Bacillus subtilis lipase: A minimal alpha/beta hydrolase fold enzyme. J. Mol. Biol. 2001, 309, 215-226. [CrossRef]

69. Simons, J.W.; van Kampen, M.D.; Ubarretxena-Belandia, I.; Cox, R.C.; Alves dos Santos, C.M.; Egmond, M.R.; Verheij, H.M. Identification of a calcium binding site in Staphylococcus hyicus lipase: Generation of calcium-independent variants. Biochemistry 1999, 38, 2-10. [CrossRef]

70. Wi, A.R.; Jeon, S.J.; Kim, S.; Park, H.J.; Kim, D.; Han, S.J.; Yim, J.H.; Kim, H.W. Characterization and a point mutational approach of a psychrophilic lipase from an arctic bacterium, Bacillus pumilus. Biotechnol. Lett. 2014, 36, 1295-1302. [CrossRef]

71. Kim, H.J.; Jung, W.K.; Lee, H.W.; Yoo, W.; Kim, T.D.; Kim, H. Characterization of an alkaline family I.4 lipase from Bacillus sp. W130-35 isolated from a tidal mud flat with broad substrate specificity. J. Microbiol. Biotechnol. 2015, 25, 2024-2033. [CrossRef] [PubMed] 